\title{
Kicking Round Home: \\ Atonality in the bone people
}

\begin{abstract}
Anne Kennedy
A thesis presented for the degree of Master of Arts in English Victoria University of Wellington June 2007
\end{abstract}

Supervisor: Professor Lydia Wevers 
This thesis is dedicated to my husband Robert Sullivan 


\section{Table of Contents}

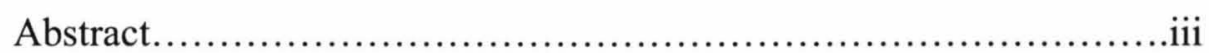

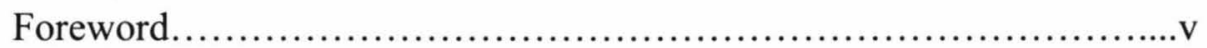

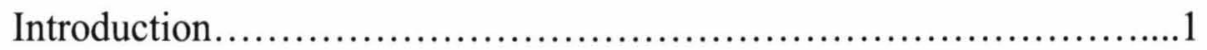

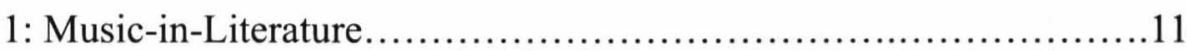

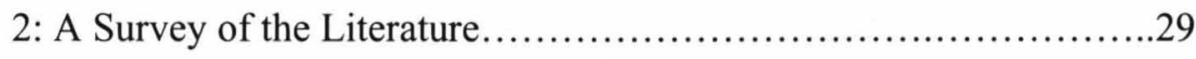

3: Music in the bone people's Narrative...........................52

4: Music as Symbol in the bone people...........................76

5: the bone people's Verbal Music..................................94

6: New Music....................................................

Appendices. I: Glossary of Musical Terms......................115

II: Index of Musical References in the bone people.......118

Notes........................................................... 132

Works Cited.............................................. 135

CD "The bone people's found compositions" attached 


\begin{abstract}
Anne Kennedy, "Kicking Round Home: Atonality in the bone people” MA English. Victoria University of Wellington, 2007.

This thesis considers the role that musical atonality plays in Keri Hulme's the bone people, and explores the ways in which an atonal reading can suggest interpretations for the novel's cultural location. From a survey of the interdisciplinary study of music-inliterature as a method, three criteria for analysing music in the bone people are identified - narratology, symbology and sound-interpretation. The thesis traces the sometimes-intersecting histories of both Maori and Pakeha music. It considers how instances of atonality in the bone people relocate Maori singing, in function and to some extent in form, to the page. A survey of critical readings shows how the bone people has often been assigned intentions of biculturalism. This thesis challenges that notion and asserts that Hulme transforms cultural ingredients of both Maori and Pakeha in an atonal space, and re-imagines them in a Maori framework.
\end{abstract}


There can be no proper rendering of Maori songs without capturing the air.

Sir Apirana Ngata (xxiv)

The absence of tonality is a sort of homelessness, a permanent exile because you're not going to come back.

Edward Said (2002 49)

I karanga to rivers.

Keri Hulme (1994 140) 


\section{Foreword}

For several years I have been drawn to the subject of "music in fiction," from fiction about or involving music (e. g., Ian McEwan's Amsterdam) to symbolic usage (of political struggle, for instance, in the work of Toni Morrison and Alice Walker), to the linguistic rhythms, "sounds" and structures that are the "music" of the text (Joyce, Woolf, Morrison, or indeed anyone!). I held, without realising it, a conglomeration of several music-in-fiction theories that were roving around looking for a host to attach themselves to. One afternoon, idly scanning the bookshelf, I came across the bone people which I had read with huge admiration and enjoyment when it came out in 1985, and again in the early 90 s. As I took the book down a sudden warm feeling overtook me; contained in this novel was all the music my as-yet-unformed theories could possibly ask for. Because of its musicality on every level, the bone people is the most pertinent subject in New Zealand literature for a musical reading.

A third and more recent reading of the novel delivered to me an aspect of music in

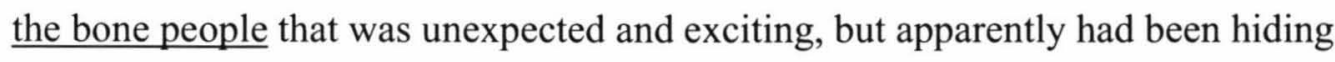
there all along - its musical atonality; in other words, its eschewing of the idea of a musical "home." I already knew that in a Western tradition, music-in-literature had been seen to function as both an organising factor and a release mechanism, invoking harmony and allowing dissonance; that blues and jazz in African American fiction had been charted for its symbolic and spiritual role; and that music was historically the lyrical basis for poetry and its off-shoots. I would use this rich groundwork as a 
starting point to analyse Keri Hulme's the bone people from the point of view of the novel's referencing of the great musical departure of the twentieth century, atonality.

The bone people has proved an extraordinary document for a musical reading, not only because of its wealth of musical allusion, but because these references appear to point somewhere beyond themselves, adding layers to the already rich blend of narrative, theme and linguistic creation that is the novel. My hope is that a musical an atonal - reading of the bone people will throw light in a useful way on the cultural components of this already much-studied work.

Finally, my deepest thanks go to Dr Lydia Wevers for her insightful and patient supervision of this thesis; to Reina Whaitiri and Albert Wendt for endless support and encouragement; also to Reina for sharing knowledge and kindly providing a Ngai Tahu waiata; to my husband Robert Sullivan for illuminating conversations and everything else; and to my son Temuera Sullivan for invaluable technical help with preparing the $\mathrm{CD}$. 


\section{Introduction}

\section{a) Dissecting rain}

When the redoubtable Kerewin Holmes reaches for a guitar for the first time in Keri Hulme's the bone people, the impulse already has the quality of a nervous tick. "For a cat, when in doubt, wash: for a Holmes, ruffle a guitar" (25). Simon, the strange flotsamboy who is to be the agent of change in the story, has recently turned up unannounced at Kerewin's tower and she finds herself at a loss. Her hand closes around her oldest instrument, but as she fingers harmonics, chords and melody, an unplanned sound saturates the music. It is "the white noise of the rain." At this point it is no big deal. A moment later, throwing in the towel on trying to engage the silent Simon in conversation, Kerewin philosophises that even if a person has taken an informal vow of solitude (as she has), they may still occasionally need human contact. She has another idle strum on the guitar, only this time the rain, as if on a mission, "responds by pissing down harder than ever."

With "the white noise of rain," Hulme has set up, early in the novel, a path for music to enter the proceedings and, within that music, the disruptive influence of atonality. This thesis will argue that Hulme uses music in its multifarious traditional Maori functions, to inform, entertain and assert a point, and in doing so presents post-contact Maori culture, with all its influences, in a Maori framework.

Each of the two elements in the scene above is portentous: Kerewin's inkling that even she might need help one day (a seemingly ludicrous sentiment to attach to the "miserable sulky dumb brat" in front of her); and the guitar chords swollen beyond 
their intended size. Throughout the novel, Kerewin's solo state is to be put on trial, and, throughout the novel, sweet music is to be challenged by unexpected sounds. Often the intruding sound is white noise, in which the spectrum of sound is filled - the sonic equivalent of white light. White noise is literally the raw material of all sound, including music. A reader of the bone people, on "hearing" rain, is left with an impression of sonic possibility. (Of course, everything to do with sound in writing will be an impression, a topic this discussion will return to.) The noisy culprit is not always nature; sometimes it is circumstance, as when the radiophone buzzes when Joe first rings Kerewin (26); in other instances it is metaphysical, such as the "screaming centre" of Kerewin's visual art (74); sometimes Kerewin simply finds herself, frustratingly, unable to play the chords that once fell from her fingers as easily as language. With this music she confounds not just herself but Joe, who puzzles, "It's not blues, it's not rock, it's not folk or imitation electronic, and sure as hell it's not any Maori music he'd heard before[...]" (240-41).

If the sounds are not the things Joe lists, what exactly are they? What work do they do, if any, in the novel? Are they some sort of code or language? Do they have any transformative effect? In short, why are they there? And, what of their absence? Where violence sits at the novel's narrative core, with Joe, there is no music.

Before attempting to address these questions, some definitions will be useful. The Shorter Oxford has music as "that one of the fine arts which is concerned with the combination of sounds with a view to beauty of form and the expression of thought or feeling; also, the science of the laws or principles by which this art is regulated" (def. 1); 
and as "sound in melodic or harmonic combination by voice or instrument." Noise on the other hand, (having traveled from its seventeenth century meanings of an "agreeable or melodious sound" (5a) and "a band of musicians" [5b]) is "a loud outcry, clamour, or shouting; din or disturbance" (def. 1). Surely the sounds that persist in ambushing music in the bone people - the sounds of rain, of buzzing and screaming, of "as sure as hell" no Maori music ever heard before - surely these sounds are "noise." Their purpose, however, could arguably be seen to be concerned with "the expression of thought or feeling." Occupying a more than arbitrary space in the sonic landscape of the novel, noise could be regarded as having very definite expressive uses. When song or rain, guitar chord or musical mistake are used with seemingly equal intent and emphasis, the differentiation between music and noise appears to break down.

I want to suggest that the frequent recurrence of noise in the bone people - buzzing, rain, static - introduces a state of uncertainty, of rawness, which dissolves to some extent tonal music and from which a new kind of music can emerge, and that that new music is atonal.

The notion of conflating noise and music is not new. The composers Schoenberg, Webern and their followers, writing in the early twentieth century as part of the Second Viennese School, broke down boundaries between noise and music (returning noise to its seventeenth century association with music). In his overview of Modernist musical trends, Leon Botstein, writing on the Second Viennese School's "perceived need to abandon old distinctions between music and noise," quotes the Italian futurist, Luigi Russolo: " "We must break out of this narrow circle of pure musical sounds, and conquer the infinite variety of noise-sounds"" ("Modernism"). 
What Schoenberg, Webern, et al did was to use the twelve tones of the tonal system and in democratic fashion, not favouring any one note, but rather making carefully arrayed patterns, so the music had no tonal centre. The patterns concerned only the arrays of pitches; rhythm and meter were not necessarily patterned. Other names for the resulting "noise" were "twelve-tone" or "serial" music. While twelve-tone compositions may sound chaotic to the listener, in fact they are highly organised, patterned and logical. Atonality constitutes the great musical departure of the twentieth century. Despite the coexistence of tonality, there has been no going back from the concept of atonality.

Finding music in the raw material "noise" is something Hulme addresses directly in her memoir, "Okarito and Moeraki," in which she comments on the varied sounds of different stretches of coast: "To me[...]it is the land and the sea working against one another, warring, and singing while they do it[...]e te hoariri, kei te pai. And the seasong at Okārito harmonises perfectly with the seasong of my heartplace, Moeraki" (8). The kind of harmony Hulme seems to be talking about is not tonal, but a blending of noise upon noise, a music organised from the apparent chaos of the spectrum of notes.

It is my contention that the concept of noise as raw material and atonality as its offshoot is embedded in the narrative, symbols and sounds of the bone people; that music in the novel moves from tonality towards atonality and back again, but with notions of tonality changed. Further, that the presence of atonality in the system of the novel places it in time and culture. If Western tonality is the set of notes that sounds tuneful to our western ears, atonality is its deconstructed, "untuneful" opposite. When tonality is usurped by a centreless atonality in the bone people, the translation, I suggest, becomes 
emblematic of good old-fashioned deconstruction. With a new model of multiple centres set up, any idea of a fixed "home" is made redundant.

b) Music inhabits the book

With the publication of the bone people Hulme joined a tradition of writers of "musicalised" fiction which includes Joyce, Proust, Thomas Mann, Virginia Woolf, Toni Morrison, Vikram Seth, and Roger Mais, to name a few. Each of these writers has engaged with music in ways that differ as much as genres of music differ from each other. The bone people's idiosyncratic use of music is, ironically, true to form. Its particular alchemy of music and text has everything to do with the author's cultural history. In the bone people, I would like to argue, Hulme relocates the Maori song, in function and to some extent in form, to the page.

The methods by which we read - or hear - music-in-literature has been discussed by theorists from Adorno to Barthes to John Cage. Calvin S Brown, a pioneer of music/word studies, brought the field under the umbrella of intermediality, and has been followed in this work by Lawrence Kramer, Steven Paul Scher and, more recently, Werner Wolf.

From a liberal humanist point of view, Bettina Knapp ascribes the phenomenon of synesthesia (the Romantic idea of fusing the senses) to music-in-fiction. Knapp also draws on Jung's notion of archetypes to assert the psychic function of music-in-literature, where our allegedly inherited reception of archetypes extends to the symbolic power of musical archetypes. 
Daniel C. Melnick, writing on the dissonant aesthetic embraced by modernist novelists, sees music-in-fiction as functioning as both an organising agent and a release mechanism, invoking harmony and allowing dissonance. Highlighting the early twentieth century move away from the Romantic idea of music-in-fiction as mere ornament, Melnick makes socio-political claims for the emergence of dissonance (a set of tones considered untuneful and requiring resolution) in literature; dissonance was achieved in the text by, among other things, parody, fragmenting and the absurd. An industrialised and militarized Europe, according to Melnick, was a driving force behind the modernist narrative whose "destabilising dissonance [became] an index of the potential for a freed life in the face of order[...]" (126).

Fundamentals of these theorists' methodology suggest three jumping-off points for a musical reading of the bone people.

The first method is to analyse the novel from the point of view of its narrative. Kerewin's carefully constructed solo existence undergoes a form of "whiting-out" by the arrival of the urchin Simon, his foster-father Joe and their turbulent world of loss, need, love and violence. Atonality can be associated with "what happens" in the bone people.

The second approach is to look at how music infiltrates the bone people in direct musical references used as symbols: Kerewin's guitar and its adopted masculinist position in Maori society, Simon's unearthly singing and its association with the spirit, pub singing and its lode of community, renditions of waiata and their connection to the neocolonial space. ${ }^{1}$ In its symbolism, the bone people is seen to engage with archetypes. In Joe's "It's not blues" speech above, music and spoken language appear to be being 
placed in a simultaneous equation. All through her text, Hulme draws on a miasma of literary and musical, formal and colloquial symbolisms, from Christianity to Fantasy to New Ageism. These references defy a centre.

Lastly, the bone people can be read or heard as an intensely musical novel simply by the way it "sounds." Its use of a rhythm and of an array of complex phonemes - fricative, guttural, sibilant, liquid - functions like orchestration. In tandem with meaning, our ear is engaged by the text on an aural level. Voice in the bone people - or rather voices - calls on both constructed and found language in a way that avoids centrality and which instead associates itself with an array of centres. Voice in the bone people can be read as a musical entity, specifically an atonal one.

But what to do with this information? One of the aims of an atonal reading of the bone people is to consider what these atonal references, as a modus operandi, uncover in the novel in terms of cultural and political indicators. Where dissonance implies an eventual return to harmony, atonality is a different language altogether, one that constantly defies a centre; atonality literally tosses the centre away from itself towards the margins, again and again. The atonal, it seems, engages with what Gayatri Chakravorty Spivak identifies as misrepresentations of marginality. Her definition of the "constantly changing set of representations" manufactured from the hegemonic centre (1993 62), is what the bone people appears to challenge. Where Spivak argues for a rearrangement of the notion of marginality, atonality likewise explodes at once both the myth of the centre and of the margin. Exploring the bone people as an atonal novel will perhaps reveal a similar model of centrelessness. 
Certainly the use of non-tonal music in the novel moves it beyond early twentieth century dissonance (which subscribes to a centre) to late twentieth century atonality; beyond modernism to postmodernism; and, inevitably, into postmodernism's subset, neocolonialism. It is at that junction that at least some of the "bones" of the bone people lie. Revisiting the boundaries exemplified by Kerewin's first guitar chords - boundaries between music and noise, between harmony and disharmony, between the expected and the surprising - the notion of home or centredness will again be called into question.

\section{c) The uninvited guest}

By portraying Kerewin Holmes as a woman artist, albeit a visual one, Hulme leaves the door open on the symbolic and transformative possibilities of sound. Kerewin is, as Susan Ash has suggested of Frame's Carpathian heroine, "the woman artist who writes, paints, plays her way towards a self-identity that has been denied her" (125). A confounding factor in this argument is that Kerewin is not just a woman artist, but a failed one. This "failure" allows art in the guise of atonality to come in the "back door" of Kerewin's artistic ambition - she's not really "trying” at music. Hulme's failed woman artist takes on as her ideological opponent more than she bargained for. There is the implied notion of "womanhood," but also of language, through the shared space of music/sound/text. It is in this space that the renegotiation of culture can take place.

The rags-to-riches story of the bone people long ago passed into literary legend its repeated rejection by the "big publishers," eventual acceptance and publication 
by the fledgling and woman-centred press, Spiral (which sold its entire first edition in a matter of weeks), its winning of several awards including the New Zealand Book Award for Fiction, and of course its 1985 win of the Booker Prize. The novel's mythology has taken up residence outside its covers, where it has been much admired and critiqued for its themes of gender, race, loss and violence. Conversely, its author has been located inside the book by the widely-discussed suggestion that she might be the prototype for Kerewin. At the same time, the authenticity of both novel and author has been called into question, notably by C. K. Stead, who in 1985 accused Hulme of not being Maori. Mark Williams questioned the novel's embracing of things Pakeha and its "positive and possible model for the future" (104).

Given that Pakeha readers, it appeared, had had no trouble swallowing the notion of Maori village life in Witi Ihimaera's early fiction, nor did they question the authenticity of Maori violence as a theme in Alan Duff's Once Were Warriors, I will analyse, via the bone people's engagement with atonality at all its levels, these troubled readings - which perhaps result more from consternation at alleged Maori annexing of "European" texts, rather than a wish to preserve perceived standards of authenticity in Maori writing. ${ }^{2}$

A scramble for cultural territory outside the novel raises the issue of a possible tussle going on within it. There are two thematic strands which have their expression in musical references; one, societal (represented by community singing and Simon's archetypal singing); the other to do with selfhood (Kerewin's guitar-playing, Simon's silence). The two are, of course, intertwined. 
Kerewin might appear to live freely, but in fact she does not. She may live alone and aloof from economic concerns, having won a large sum of money, but her capitalist windfall ties her at the same time to the economic and other structures of the nation. The reader can deduce from Kerewin's range of cultural accessibility, that colonisation is a part of the novel's back-story. Hulme places Kerewin in what Homi Bhabha has identified as the liminal, hybrid space between colonised and coloniser. At this interface, culture happens: "The production of meaning requires that these two places be mobilised in the passage through a Third Space" (53). This shifting space, existing because it is written, or painted, or sounded, has - as with atonality - no centre.

Returning to the sound story with which this introduction began, in which Kerewin's carefully fingered guitar chords are intercepted by noise, I can now attend to the music that grows out of that noise - that is, atonal music - and to examine its impact. In this thesis I argue that the bone people Hulme deconstructs harmonic or Western tonality and introduces its uncentred alternative, and that in the process she relocates the Maori song, in function and to some extent in form, to the page. 


\section{Chapter 1: Music-in-Literature}

\section{a) Song parcels}

Music and literature have had a symbiotic relationship as long as language arts have existed. Across every culture music has acted as an aid to memory in mythical tales, religious expressions and genealogical histories. The memorable quality of song over the spoken word encouraged the pre-literate wrapping of word-messages in notes. Homer, the "blind poet," allegedly sang or chanted his epic narratives. Early Hindu chanted the Veda in Sanskrit to pass on religious and philosophical knowledge. The early Western Christians arranged sacred texts in meditative stretches of melody called Plainsong. Plainsong later developed into Gregorian chant, named after Pope Gregory IV, who in the sixth century requested its formal adoption ("Plainsong" Oxford). The Gregorian melodic tropes drew on the Greek modes, which were five-note sets or scales, each with a particular humour. Gregorian chant, although extemporaneous in style, was repetitive rhythmically and melodically and centred closely around a home note.

Pre-contact Maori also chanted using a small range of notes (which might include microtones) to facilitate memory (McLean 236). McLean makes a distinction between the non-pitched chant (as in the haka) and the pitched, which included the karakia (prayers), recitations of whakapapa (genealogical narratives), and the karanga (call onto the marae). Pitched chants were (and are) sung in patterns of a few notes, not always definitely pitched but hovering around a central oro or intoning note. Mclean describes how "each melodic departure from the oro is ordinarily followed by a return to it" 
(235). This pattern has similarities to the Gregorian chant model. McLean goes on make the point that although parallels in the musical history of Maori and Pakeha are not certain, there appear to be "shared principles" of music between the cultures (237).

For Maori before European contact, song and chant had important societal functions, as part of the everyday and of ritualised interaction around welcoming, entertaining, informing and mourning. There were four main categories of song: lullabies, laments, pātere (songs of defiance), and lovesongs (Ngata xxv-xxvi). The way a song was put together (its rhythm and tonality) depended on its usage (Orbell 1). If a point was to be asserted, the song was recited, either pitched or unpitched, rather than sung. On the other hand, emotional expressions, such as love or sorrow or even teaching, were sung in a more melodic form, so that a child might learn part of their whakapapa in the melodic oriori. The most publicly sung versions of Maori song were the waiata, melodic songs with a limited range of notes, but with elaborate language designed to persuade, cajole or express the poet's feelings of love. A woman might compose her own waiata to deliver a message of love to a man. A rangatira might quote a wellknown waiata to make a point in a speech. (Orbell 3).

Many examples of early music from all over the world are still extant, albeit often in formal situations. Some Western Christians still regularly sing Gregorian Chant. Where Maori music is concerned, both form and function of traditional chant and song have traveled into the present. When Maori gather in both casual and formal settings, song is used to welcome and, in reply, to accept hospitality. The karanga onto the marae is perhaps the most well-recognised example of contemporary Maori chant. In the 
karanga, a kuia or female elder welcomes visitors, and in the same chant recalls ancestors and sets the agenda for discussion, often in an illusory manner (McLean 29).

Although Maori song and chant have gathered around them the influence of European, and now global, contact, Maori music designed to convey specific meanings, both sacred and secular, continues to be an integral part of Maori daily life. ${ }^{3}$ Maori, it appears, have not gone all the way through the door, described by Barthes in Image/Music/Text, that polarizes populations into performers ("the interpreter to whom the bourgeois public... delegated its playing") or passive listeners (163). Hulme herself, in an interview with Harry Ricketts conducted before the Booker win, claims "if you were brought up in the Maori way and you had the drive to play with the words, you turned them into waiata, or song poems" (28).

\section{b) On the page}

That the transition of language arts from the aural to the page has often retained links to music may not be surprising for poetry, which more often than not maintains its association with the aural through rhythm, and decorative techniques such as alliteration, but also through the potential for performance. What is more intriguing is that a novel, written to be read alone and silently (the reader rendering a solo piece of motionless performance art, to no audience) could ever be thought of as going hand-inglove with music. How can music have any relationship with literature at all when the former is shifting, physical and has frequency (pitch), and the later is fixed-in-time, non-pitched, and intrinsically - physically - silent? 
In the late sixties the novelist Edward Kamau Brathwaite, after asking himself much the same question, pinpointed the commonality that had allowed jazz to enter the West Indian novel as "those passages[...]that grapple most closely with folk forms and folk experience, [also] contain elements of improvisation" (327). Brathwaite goes on to draw parallels between the improvisational nature of jazz (improvisation being highly patterned, discursive flowerings off a repeated theme) and the language-patterns of some West Indian novelists. Braithwaite directly addresses the concerns of how music can influence writing on rhythmic and structural levels. When he refers to writings "that grapple" with the implication is that there is some sort of struggle attached to the marrying of "literature" (the written) and all that "folk" encompasses (the found). Brathwaite is arguably making a case for the connection between physical sound and silent writing being a relationship that strives for meaning beyond the writing.

What this idea opens up is the possibility of dimensions beyond the more concrete use of music-associated language patterns.

In tandem with the dual modality for Maori mentioned above, the chant underwent a post-contact transition to the page. This process is well-documented. In the early part of the twentieth century, Sir Apirana Ngata collected the enormous body of work that is Nga Moteatea. These gatherings of laments and songs, bear witness to the close association between music and text for Maori; but not only music and text, also the notion of tapu and noa, sacred and profane. The process has been fast, in relation to the European transition which had a long period of the development of the secular song. In addition, literacy for Maori happened very soon after contact with Europeans, and so 
existed for a time cheek-by-jowl with a traditional way of life. This may point to conditions that were ripe for cross-fertilization between words, music, sacredness, and the text.

If we look at the bone people in relation to its place on a continuum of culture in general and of word/music history in particular, we can consider some factors: that its author comes from a tradition that inculcated Western tonality into its communal oeuvre soon after being exposed to it; that that phenomenon is not very far in the past; that a binary system of tonalities, to be slipped in and out of, often on the same occasion, was established; that the author of the bone people comes partly from a tradition where the sacred chanting of words is ongoing and contemporary. Given these circumstances, it would seem strange if the bone people were not a work that took on music along with its words.

\section{b) The rise and partial fall of tonality}

The history of tonality is important to this study, because it charts not only the development of musical sound but also cultural movements, which in turn reveal just how major the move away from tonality has been. The curious thing about music is that it occurs in nature, like the wind, but it is heard, or read, as signs. The shift to atonality, then, is really just the same notes reread. We might reread in the way of Bhabha, with the idea that cultural indicators have no inherent significance and "even the same signs can be appropriated, translated, rehistoricized and read anew" (55). 
Western tonality begins, in theory, with Pythagoras' music of the spheres, or the "belief in a universe ordered by the same numerical proportions that produce musical harmonies" (Haar). Pythagoras (c 580-490 BC) made analogies between musical consonance and the natural phenomena of the harmonic series (the notes that combine to make up pitch and timbre or tone): he found that by plucking a lyre string, then halving the string by depressing its centre and plucking one half the length, a note one fifth higher was produced (Barbera). (This interval can be made real by singing the first two notes of the music to 2001: A Space Odyssey, Richard Strauss' Also Sprach Zarathustra.) When the halved string was halved again, a note a fifth higher again was produced, and so on through a series of halves and fifths until a note the equivalent of the original note only several octaves higher, and thereby completing an early version of the Circle of Fifths (Drabkin). By shuffling all these notes together into a single octave, what we commonly call the eight-note scale (although the highest note is a version of the lowest note) was produced.

The development of tonality was an incremental process that took many centuries, from limited-note modes (exemplified by Gregorian chant) to the broader tonality of the eight-note scale The modes used by early Christians became more and more embellished over time, until the range of notes was stretched. By the twelfth and thirteenth centuries, the songs of the lyric poets of the South of France, the Troubadours and Trouvères, were employing a larger range and variety of notes (Karp). Over the following three hundred years, musicians experimented with "tempering" the scale, that is, the slight altering of the pitches of some of its notes so that all the scales could be uniform. This allowed for shifts in tonality (key changes) within compositions, and for 
ensemble playing because instruments could be tuned to the same pitches

(“Temperament" Oxford). It was not until the 1600 s that J. S. Bach with his WellTempered Klavier standardised the full range of the eight-note scale across forty-eight keys. It is notable that the move towards standardized tonality was accompanied by a shift in music from the sacred to the secular in European music.

Today every genre of modern "Western" music uses Western tonality, from the Classical tradition to reggae to rap to the modern waiata. This tonality, so amazingly uncovered, pushed, prodded and systemised over the centuries, is what atonality makes its departure from.

By contrast, Maori adoption of the eight-note scale was sudden and followed exposure to the tonality through European contact - as is the pattern for many cultural elements on contact and colonisation. The new tonality had a profound, widespread and lasting impact on Maori music, as it did all through the Pacific. Listeners may imagine contemporary Maori musicians who sing in te reo and are part of mainstream popular culture - such as Nesian Mystik and Aria - to be the sole inheritors of Western tonality, but the modern waiata was born of the same fusion. The modern waiata, used on many public occasions both formal and informal by Maori (and sometimes by Pakeha) in Aotearoa, is a post-contact phenomenon. The music for many well-known waiata was written by the white Australian composer Alfred Hill in the early part of the twentieth century, but by far the largest number of waiata have been and continue to be composed by Maori, often for specific purposes.

Maori chants that employ the original limited range of notes, however, remain an important part of contemporary Maori life. The karanga, although shortened, is used 
widely as a welcome onto marae. The kapa haka is hugely popular, with both traditional and contemporary works being performed at many gatherings, the largest of which is the biennial Te Matatini Kapa Haka Festival. Kapa haka are still used to deliver a message, such a the anti-smoking haka.

The crucial fact here is that Maori music today operates with binary modalities; the western eight-note scale (characterised by the popular waiata) being used alongside, but separate from, the traditional modal chant. This duality is true for many peoples as a result of cultural colonisation. As an example, in Japan today pop bands sing to Western tonality while traditional Japanese music survives.

\section{c) Music-in-fiction: further readings from the field}

Armed with the history of the development of Western tonality and the concept of music as an element of literature, we can consider how some critics have theorised about music in literature based on analyses of writings. Most theorists agree that music is referenced in literature in multiple dimensions, from the concrete to the symbolic, but analysis has covered a fairly wide range of approaches.

Calvin S. Brown, a pioneer in word/music studies, defined the field as part of intermediality in his seminal 1948 essay, "Music and Literature" (Wolf 5). Lawrence Kramer continued Brown's work (labeling it "melopoetics") and read into music meanings which could assume the role of " "condensing' larger dramas of social and cultural identity" (52). Western music had been seen as an entity cut off from experience and from other cultural expressions. According to Kramer, however, music 
is read, not for what it says, but for the way in which it re-enacts the audiences' experience (7). Kramer is saying that music cannot be separated from the rest of culture, but is part of the dialogue of signs and symbols.

Following in these cultural studies footprints, Steven Paul Scher, working over a forty-year period from the late 1960s on, devised categories within the two poles, "words" and "music," which focused on their various emphases (28). "Music-inliterature" encompassed fiction, "Music and Literature" was epitomized by opera, and "Literature in Music" described program music, or music that tries to illustrate a narrative. Scher entertained the notion that our engagement with words and music slid back and forth between music and not-music: "If we are to understand the cultural power of music we must also study the listeners' plots" (479).

Most recently, Werner Wolf in The Musicalization of Fiction, takes a structuralist approach to word/music intermediality, considering, among other things, how music in a text takes on varying roles, acting as metaphor, as signifier, as other. "Music is something other than, if not the 'Other' of, literature" (33). Accordingly, Wolf sees the role music plays in fiction as being metaphorical and symbolic (52). For Wolf, the study is endlessly available to sub-categorising. Evidence for identifying musicalised fiction can be broken down into the circumstantial and the textual, the overt and the covert, the intentional, and the evocative (83).

Calvin, Kramer, Scher and Wolf confined themselves almost exclusively to the study of European or Western music and literature.

Daniel C. Melnick takes on the issue of tonality in his study of dissonance in fiction (where dissonance is the moving away from harmony towards clash). Analysing late- 
nineteenth and early-twentieth century fiction from the point of view of how musical and in particular dissonant - references occur in narrative, symbol and sound, Melnick comes up with some cultural readings. With a backdrop of the Romantic philosophies of Rousseau, Schopenhauer and Nietzsche, Melnick looks at music in Proust, Mann and Joyce and finds that the Romantic aesthetic of music in literature as "beautiful" is replaced by a harsh modernist dissonance, which disrupts and fragments the narrative (8). Melnick calls on Adorno's notion of dissonance in literature as protest (9). When harmony and innocence give way to a knowing jarring, that musical chaos mimics the social upheaval of nineteenth and twentieth century Europe - the aftermath of industrialisation (which was, in itself, noisy) and war. Where harmony is natural and Romantic, dissonance signifies a modernist removal further and further from nature (6). Melnick reminds us that the nature of dissonance is that it exists because harmony is there; it almost always resolves back into harmony.

Applying this model to Joyce in particular, Melnick attributes the quality of redemption through dissonance to Joyce's engagement with the turmoil of his world. "A parodic dissonance in [Joyce's] fiction is a risk-taking attempt to construct an affirmation of enduring consciousness out of the disorder of his time" (8). In $\underline{\text { Musical }}$ Meaning, Kramer echoes Melnick's notion of a radically transformed "use" of music and sees high modernism as signaling the end of classical music: "Audiences cannot hear the music[...]what they hear is the apparatus: is modernism" (271).

The Europe Melnick is talking about was arguably engaged in a furious shaping of its own idea of itself as an entity, perhaps as a kind of "West." In this light it is interesting to note that Barthes, in Image/Music/Text, finds the structural features that 
are the hallmarks of Romanticism (contrast in intensity, the disassembling of melody, the use of chimera) to be "all musically acceptable since always deployed under the authority of the fundamental code of the West, tonality" (151-2). If tonality represents an idea of the "West," what could atonality (and its occurrence in the bone people) represent?

Amplifying Melnick's use of the symbolic, Bettina Knapp considers the metaphysical in music through the notion of Jungian archetypes. Carl Jung's theory of the archetype, where characters representing certain human traits are seen to be held in common between cultures and through generations, has of course been a major component of modern philosophical thought since the early twentieth century, when his writings appeared. In Knapp's book, Music, Archetype and the Writer: A Jungian $\underline{\text { View, }}$, she incorporates Jung's idea of the "inherited mode of psychic functioning" into the area of music-in-literature (3). Referencing Edward Edinger's claim that "an archetype is to the psyche as an instinct is to the body," Knapp proposes that a shared and inherited memory of music has an effect on our thinking and therefore our writing:

Like the archetype, archetypal music is endowed with energy tones which decide repetitions, modulations, leitmotifs, associations, multiple variants, and combinations that underscore the emotional valves or condition of the novel, drama, or poem being composed. (3)

Knapp acknowledges a mysterious element to the process by which music is transferred to the psyche. For her, pitch, rhythm and event provoke mood changes on the surface of our psyche, and in turn delve into the contents of our subconscious. But she draws on the physical connectedness of music, the music of spheres, where the 
phenomenological experience of music could be transcended to a theoretical or imagined world of physics - the behind-the-scenes goings on of the physical world. The notion of archetypes suggests an invisible transference of narratives, characters and scenarios, through music. She allows us both mythical and mystical readings of music in literature. Invoking Aristotle's concept of form forever realising itself into matter, Knapp concludes, like Melnick, that "music is one way of organising phenomena - one way of bringing into being a chaotic entity" (36).

Knapp's theory encompasses the notion of synesthesia (also called upon by Melnick), originally a Romantic idea of integrating opposing sensory and intellectual experiences, whereby a smell could be touched, a colour heard, a sound read, and so on. Knapp applies the notion to modernist fiction. In a reading of Sartre's Nausea, for instance, Knapp finds that "music is sensation and feeling; it is texture and resistance; it has become thingified" (140). Further, Knapp sees a simple equation between synesthesia and abstraction. When an object or idea is separated from its "usual habitat[...]the usual comparisons [can] not be made" (82). This model of disengagement makes a useful point of reference for an atonal reading of fiction. In atonality, notes are abstracted, or extracted, from their harmonic home, both in terms of physics and cultural expectation. In the bone people, both musical references and wider cultural references can be read as operating outside their "usual habitat." It is this characteristic that appeared to intrigue and incense some critics of the book.

Yet Hulme is one of many artists from Aotearoa who have worked with the concept of synesthesia. ${ }^{4}$ Her synesthetic process has not been embarked on, it seems, without awareness. Hulme has described in detail how she engages with combined senses in her 
work: "I have a visual and aural imagination. Sound and sight are formulative processes. Writing involves listening and looking" (O’Brien 23). In a further conversation Hulme discusses the interrelatedness of drawing, writing, playing the guitar, walking on the beach, and even eating - all pursuits that feature strongly in the bone people (Alley 148). Revisualisations, according to Hulme, come with "sound accompaniments".

Like Brathwaite's idea on the transcending role of sound in Caribbean fiction, Saadi Simawe points to the liberating possibilities for music in a text that may have other language strictures, of class, gender and association imposed upon it from outside. Writing of African-American use of jazz references in fiction he argues that fiction writers

can escape the inherently ideological bent of language. Because it is almost impossible to separate spoken and written language from ideology, antiestablishment writers find in music what they view as absolute freedom of speech and of thought. (xxii)

Simawe's notion of a liberating reinvention of language echoes the political claims Melnick ascribes to the use of musical dissonance in music.

The work of the theorists outlined above has been important in helping to formulate a methodology by which to approach music in the bone people. In particular, Brathwaite's notions of the transcending qualities of musical sound in fiction has been influential. Melnick's study, focusing as it does on the specificities of tonality, makes 
an important precursor to an investigation into atonality in the bone people. Melnick's method of reading the political and social into dissonance in fiction precedes an atonal reading of the bone people. I have identified (as outlined in the introduction to this thesis) three criteria for a musical reading of the bone people, and in Chapters 3-6 will analyse the novel in terms of its narrative, its symbols and its sounds. As the three characters of the bone people find their various states of homelessness challenged by each other, I hope to see how and why atonality creeps "like a thin worm through the harmony of their embrace" (6).

\section{d) A note on naming}

Having set up ways for examining the text and identifying its elements in this atonal reading of the bone people, and in the light of Brathwaite's notion of a "grappling" between the new and the folk, I will take moment to discuss naming as part of this process. Brathwaite is talking about a literature and a musical genre that grew up in the same place, the same culture, albeit with an influx of influences. The novel as a form was arguably assimilated into Caribbean literature, and, for that matter, into a Maori world. In considering music in the Maori novel, whose language will be used? There are two prongs to this issue. One is that music is a "natural" phenomenon. A note is a note is a note. It has a physical make-up much like a ray of light has a set of physical particularities no one can argue with. Any naming in music invokes physical truths, as described by Pythagoras, who named mathematically the circle of fifths that had always existed in nature. On the other hand, the methods and vocabulary that might be 
employed to name, categorise and analyze that note is entirely cultural. As a Pakeha reader I am using a Western methodology to read a Maori novel from a music-inliterature point of view. This conundrum could be seen as being reflected in the very text I am considering; that the bone people arms itself with a rich texture of Western influences to create its particular cultural milieu. It is perhaps only by recognizing our own cultural biases that we can name the world we find ourselves in.

This issue of naming tonality is important in this discussion because musical references in the bone people will often be interpreted as coming under the umbrella of Western tonality (as is the modern waiata and popular contemporary Maori music, but not contemporary chant). It makes more sense, if one is to approach the neocolonial as a theoretical space, to regard this tonality as a shared tonality. In an attempt to avoid the pitfall of assuming superiority by naming, I will from now on refer to the "Western tonality" described above as "harmonic tonality."

\section{e) The age of atonality}

If the shared musical history of Maori and Pakeha was one of a path towards harmonic tonality, the nineteenth and early part of the twentieth century were, for Europeans, a move away from harmony towards dissonance. It has to be added that this shift was confined to so-called elite circles; the Classical tradition in music that had been handed down from Bach, Beethoven, Brahms et al ("the three Bs"), had split off slowly from folk music, mirroring the extraction of the written word from its folk roots. That atonality was the great new wave of the twentieth century European classical 
tradition is evident in the works of almost all of the leading composers, namely Webern, Berg, Schoenberg, followed by Stockhausen and John Cage. The rise of electronic music for the avant garde signaled a move towards atonality. In the Electronic Music Studio (where, for instance, Douglas Lilburn located himself and his work for the last third of his life according to Norman [400-412]) the world of raw sound, of white noise, of musique concrete (recorded natural sound) musical pitch had lost all its associative bearings.

It will be useful here to understand the technical differences between harmonic tonality and atonality. Harmonic tonality is based on eight-note scales that make up what we call a "key." Each key favours heavily its "home note," which it returns to frequently, and especially at the end of a composition. This is true even if the key has been strayed from in the course of a piece; it will almost always returns to its original key, and therefore, home note. The set of eight notes making up a key can be transposed forty-eight times to make other keys. In other words, the same patterning of notes can begin on any other note; it can be altered to sound minor ("sad") as opposed to major ("happy" or "bright"), and can travel between any of those forty-eight keys. If a piece of music using only the eight notes of the $\mathrm{C}$ major scale (or any other of the forty-eight scales), were to stop suddenly in the middle, a listener would be able to have a good go at guessing the next note and the note that the piece would end on. It would feel natural; it would sound like home.

In atonality, all the twelve notes that make up the forty-eight keys of harmonic tonality are used democratically. No key or home is selected from among these notes. If 
we were to make a piece of music using these twelve notes as a sequence, and being careful not to use any one note more than another, the composition would have no home or centre. If we were to stop in the middle of our piece, a listener could not guess the following note, or the note the piece might end up on.

It is true that popular music, with its enormous slice of the music market, has stayed resolutely on the path of harmonic tonality. People like a tune - they like the Music of the Spheres, the natural world of music that resonates physically with everything around them. But there are instances in popular music of divergences from harmonic tonality. The Beatles' "A Day in the Life," voted their most-loved song, begins with a cacophony of sound that is as atonal as any twelve-tone sequence. There are also instances where harmonic tonality is "roughed up" with dense clusters of sound, such as in Samoan Christian vocal music, which creates a fusion of harmonic tonality and traditional chant.

Would Hulme have listened to atonal music? I suspect not, and I make my assumption based on the fact that she does not write about atonal music. Her characters do not sit round listening to Stockhausen, or Samoan chant. They would undoubtedly have come across the Beatles, in the world she places them. Where music is named in the novel, as a phenomenological reference in her texts, it is a waiata, a sea shanty, a reel, or the "Pavane for a Dead Infanta." None of this is atonal. But all the same, atonality makes its presence felt - or heard - again and again at dramatic, symbolic or transformative moments in the text. 
There is evidence to suggest that shifts in consciousness take place across populations. So Hulme's eschewing of harmony, her embracing of the atonal, is not, perhaps, based on the experience of atonal music, but on a summoning of the archetypal narrative and its attendant music. What I want to suggest is that Hulme moved with the twentieth century drift towards atonality, in an archetypal fashion, towards atonality; and that the bone people, because of its atonal nature, is a representative document of the late twentieth century. 


\section{Chapter 2: A Survey of the Literature}

\section{a) Land!}

An excerpt from an early review by Joy Cowley in The New Zealand Listener begins, "I have been waiting for this book, watching the earth, knowing that it had to come" (60). Cowley's passionate response to the novel epitomises that of many critics, both for and against.

The dramatic entry of the bone people into the world of readers has been almost as exciting as the narrative itself. After twelve years in the writing, the manuscript was rejected by several "big publishers" who wanted to edit the large manuscript. Hulme declined. The book was then taken on by the woman-centred collective, Spiral, which received, among other grants, an endowment from the New Zealand Literary Fund, a government organisation. In a co-operative enterprise typical of the times, students were called in to help with typesetting. The novel was launched at the Wellington Teachers College in 1984. This first edition of four thousand copies sold out in a matter of weeks and the novel had already been received with critical, if contradictory, acclaim in Aotearoa before it went on to win the Booker Prize in 1985.

This chain of events is not merely interesting for its own sake, it is the first reading of the text; an auspicious one which indicates a mythology of the bone people which took up residence outside its covers. The novel has gone on to be hailed as groundbreaking and visionary. It has been attributed change-making political powers. Critics have searched the novel for indicators as to its genre - realism, magic realism, myth. They have found themes of indigeneity, gender, love and violence. But perhaps 
the most vigorous debate has centred around views of the novel's positioning on the post or neocolonial spectrum. Is it a Maori novel, or an indigenous one? Does it espouse biculturalism or self-determinism?

From the plethora of literature written on the bone people over the past twentyfour years, I have chosen texts which seem to me to subscribe to common threads of decoding and debate, and which indicate the polarity of opinion the novel has engendered. Interviews with the author are included here, reflecting Vilsoni Hereniko's "Talking Chiefs" model. ${ }^{5}$ I have also, of course, highlighted the few musical readings I have found because these, where they provide metaphorical illuminations, relate to my own study. It is precisely this intersection - of the musical and other language- or motif-associated readings, and cultural and political readings - that will inform the further chapters in this discussion.

\section{b) Wounder and wounded}

A potted version of the main narrative thread of the bone people, if we are to assume back-story, could go something like, "Man beats boy. Boy meets woman. Woman saves boy, man and self." It follows that much of the literature around the bone people focuses on this violence and its associated dichotomies; with loss and hope, victimising and bullying, with transgression and redemption.

In "Love's Wounded Beings" Anna Smith considers "new discourses of love," seeing the novel as a domestic microcosm within the wider "postcolonial" world. She links perceived postcolonial freedoms with a "freedom from worn-out narratives of 
human relationships" (142). Couple love is dead, at least for the characters in the bone people. Further, Smith links the new ways of being which will be necessary to redefine these worn-out narratives to the very language of the novel. She points to a ritual of language being created in the novel's poetic opening passage, in which words "acquire sacramental qualities that must be read as mediating the trauma of loves, sorrows and joys" (144). Smith attaches no romantic illusions to her idea of the bone people as a radical-domestic tract. Kerewin, she writes, is "no Aunt Daisy, for all her recipes" (145) but is instead self-absorbed and even pompous. What Smith is talking about here is Hulme's authorial distance which allows the reader to stand back and be sympathetic to a complex and embattled character. Anna Smith reads Christian models in the "holy family" of Kerewin, Joe and Simon, and invests Simon's beatings with sacrificial intent. But this motif goes further, according to Smith, pointing not only into the world outside the novel's domestic framework but outside the postcolonial world, to one of its tributaries: "On Simon's body we literally see the seams of civilization" (152). (My emphasis) Expanding her reading of the body as the site of transcendence, Smith sees the final assault on Simon as being generated by Joe's realisation that the boy has got in the way of Joe's hoped-for sexual relationship between himself and Kerewin (157). Smith's notion of "new discourses for love" encompasses the solution for uncoupling as lying in the land: "The land and its spirits that bring new hope" (158).

Otto Heim, in his rather negatively-titled Writing Along Broken Lines, tests the work of several Maori writers - Grace, Ihimaera, Duff and Apirana Taylor and Hulme - for signs of violence. Just as Anna Smith saw a proposition for new forms of love in the 
very language of the bone people, Heim makes case for "intricate linkages between violence and language" where Hulme uses "a language that is both a weapon and a tool" (58). Hulme's richly layered intertextuality, according to Heim (again echoing Anna Smith), achieves the quality of ritual in the "patient exploration of the three protagonists" involvement in violence. But Heim also cites direct references to an ironic word-fist connection in the novel, where Joe beats his son because it is "the only way to get the message across" (58).

Heim is talking about the relationship between intent and language. He sees Hulme as using a linguistic solution to an, in essence, political problem. According to Heim, Maori writers have found themselves restricted to two inherited and conflicting "discursive archives" - on one hand the realistic Pakeha canon, and on the other the anthropological text which presents indigeneity as noble or cute (my definitions) and through these definitions creates boundaries for "authenticity." Maori writers have had to negotiate a literary world where realism and indigeneity are mutually exclusive. What Hulme does, according to Heim, is bring both the Pakeha canon and the anthropological text together in a defiant postmodernity, thereby achieving a "dynamic and situated Maori identity" (106).

Heim disagrees with Williams' reading of the bone people as condoning child abuse, suggesting that Hulme portrays Joe not simply as a one-dimensional villain, but as a complex character, caught in the helpless love between himself and his adopted son (63). 
In "Looking Awry: Tropes of Disability in Post-colonial Writing," Ato Quayson interprets Simon's muteness as a disability (Kerewin herself, he quotes, refers to Simon as "the maimed, the contaminating" [53]), and argues for its transforming qualities in the text. Quayson outlines a theory (partly Lacanian) for a general anxiety among the able-bodied when confronted with the disabled. The relationship between the disabled and the able-bodied, according to Quayson, is pivotal to the colonised/coloniser discourse in the neocolonial novel's "struggle to transcend the nightmare of history" (66). Reading the bone people alongside J.M. Coetzee's Waiting and Ben Okri's The Famished Road, texts from opposite poles of the colonial experience (settler and indigenous), Quayson identifies the "primal scene of literary encounter" involving the able and the disable(d) (53). ${ }^{6}$ These scenes, according to Quayson, are recurring scenes in the postcolonial novel.

Although Simon is the "maimed" interloper, Quayson notes the "oscillating" boundaries of abled/disabled in the bone people. He notes that Kerewin consistently refers to Simon using "negative epithets" despite their growing relationship (63). It is as

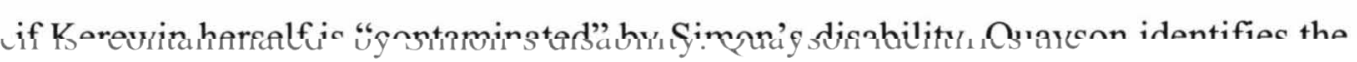




\section{c) Music and silence}

Some commentators, although surprisingly few, have highlighted the use of the binary opposites of music and silence in the bone people. Silence has also been seen to operate as the opposite of the spoken word, where Simon's muteness and notescrawling becomes a vortex for guesswork and intuition on the part of Kerewin and Joe. But it is the motif of Simon's hutch of music (a temple-like structure in which he "stores" imagined or heard sounds), that has been seen to effect development between characters.

Calling on the juxtaposed metaphors of music and silence Christine Hamelin discusses, in "Fitted to His Own Web of Music," the notion of renaming in the bone people as a method of shattering and redefining stereotypes formed around ethnic, gender and self-other dualities. Silence, according to Hamelin, is what falls between un-naming and renaming (111). Hamelin catalogues silence-clad redefinitions of identity as operating on three levels: 1) That the novel itself sets up challenges to these givens in its inverted characters. 2) That the progress of the novel suggests new possibilities, namely for a new kind of family made up of members in non-traditional roles. 3) That music and silence are used in symbolic and narrative ways to allow this transcendence. Drawing on these observations Hamelin makes an interesting connection between Kerewin's self-acknowledged thing-involved chaos - “ 'Webs of events that grew together to become a net' " (Hamelin 111) - and Simon's attempt to make the few elements available to him cohere. In a much simpler manner than 
Kerewin's, Simon gathers sounds and "fit[s] them to his own web of music" (114). In the end, Kerewin wants to "make the net whole," implying an embracing of some kind of netted expression of sound.

The culturally discursive nature of the bone people acts not only as an interpretative tool operating in the novel, but as a seeming invitation for reinterpretation. Graham Huggan in "Philomela's Retold Story: Silence, Music and the Post-Colonial novel," frames the text in terms of a debt to Greek mythology. He argues for the novel as a retelling of the Philomela story, where Philomela is raped by Tereus, threatens to tell all, and so Tereus cuts her tongue out. It is notable that this gruesome tale was echoed in John Irving's 1978 novel The World According to Garp in which a group called the "Ellen Jamesians" willingly cut out their tongues in support of a rape victim who has suffered the same fate. Both the original myth and Irving's novel set up a binary of victimhood and silence. The bone people does indeed appear to subscribe to the same powerful-victimized equation, whereby Simon's muteness makes him both pitied and uncomfortably troublesome to Kerewin, Joe, and all who come in contact with him. Huggan assumes a level of commitment of the novel to the original Philomela myth, which may or may not be the case (pointing to a Western reading inspired by the novel's "influences"). He suggests that music and silence can replace the word, which has been and still is a tool of cultural oppression; but that music and silence themselves can function in the same way. (The Ellen Jamesians, a collision of oppression and radicalism, again come to mind, even if seen from without.) Music is therefore an "ambivalent medium" and, by association, one that can transform; Huggan calls upon 
Nietzsche's notion of the entanglement of divine inspiration and a wild, Bacchanalian dissolution (16). Music, it seems, can throw all caution to the wind. Huggan isolates a piece of music referred to in the novel (the first direct reference to the actual music I have come across) - a song that Kerewin dedicates to Simon, "Simon's Mead Reel," quite simply, a wine dance. The untrustworthy, Dionysian music represents for Huggan binary implications already embedded in the linguistic mix of the text, where

music and silence conspire to reinforce an allegorical link between the voluntary submission to a willfully destructive muse and the vicious cycle of domination and submission produced by the colonial bloodknot. (17)

Huggan draws on spiritual and visionary explanations for Simon's music "hutches" (the altars where he stores his found sounds), and argues for their re-imaginative effects. They are places where "life and death are inextricably interwoven" and the sounds that are emitted hold the three characters in a "spiralling embrace" (17). It is interesting to note that the spiral, with its ever-shifting evolution of a centre reflects a concept of atonality.

Hulme herself, in a 1989 interview, "Reconsidering the bone people," makes connections between land, sea and music in the novel. Establishing the prominence of the elements - "the other two major characters [in the novel] were the actual land[...] and the actual sea" - Hulme goes on to describe how she writes poems to the land and sings to the water: "[...] when I am traveling, I karanga to rivers, I call out to rivers" (140). Hulme's observation seems a key notion in thinking, not just about the 
role of music in the novel, but the novel's function as a musical entity. It raises again the questions, why is there music in the bone people, and what does that music do?

While music in the bone people and its inverse, silence, has been the subject of theorizing by several critics and by Hulme herself, what has not been discussed to date, as far as I am aware, is what kind of music is written into the novel, and how that choice of music might be embedded in the world the novel creates, and the world it projects.

\section{c) Myths of place}

The most prevalent bone people myth, it seems, has been one concocted outside the book. Indeed, one of the most extraordinary aspects of the bone people's reception has been the idea that it posits models for how we, its readers, might live in the real world. There have been claims that the bone people offers a bicultural message, a way forward for Maori and Pakeha to live in harmony together. The novel has been touted as giving Pakeha, at long last, a spiritual and emotional accession to the land. In other readings of this "Pakehafying," the bone people has been seen to be "not Maori enough." Overall, it seems that the bone people polarized critics, and struck a deep nerve with Maori and Pakeha readers in general.

In her review of the bone people (quoted above), Joy Cowley's reference to "watching the earth" implies a metaphysical connection between Hulme's novel and a myth or myths existing outside it (60). In a similar vein Aorewa McLeod, writing in a 1986 issue of the NZ Women's Studies Journal, hailed the bone people as a watershed, 
but went further to pinpoint what was to be a crucial catch-cry, and one that stacked up critics for and against (4). The bone people was “Aotearoa's first bi-cultural novel one which draws on both Maori and Pakeha culture and suggests how we are indeed a new people."

In another early response, Merata Mita's "Indigenous Literature in a Colonial Society" questions the notion of the bone people as a Maori novel because it is written in English. A Maori novel, according to Mita, must be in Maori (4). Further, Mita sees biculturalism (in the New Zealand context) as something achievable only by Maori, not as a shared cultural space. But Mita makes no claims for the bone people as a bicultural document; rather, into Hulme's inclusion of Maori and Pakeha elements she reads a deliberate fracturing, a "refusal of certain elements to fuse" (5). Mita praises the novel for its voice, likening its layering to improvisation jazz (7). But although she notes the metaphorical excavation of the "secret" violence of colonisation, she finds the ending unconvincing and disconnected from the "concrete" or real Maori spiritual world she herself perceives. Where other critics identify an imagined Utopia, Mita sees in the ending of the bone people a tendency to "mystify Maori spirituality to the point of repression" (6).

In 1985 Karl Stead, in his essay, "Bookered," questioned the authenticity of the bone people in terms of its perceived positions on both feminism and ethnicity. Stead dispenses with any feminist creditials the novel might claim by citing its rejection for publication by three "feminist collectives" (179). He goes on to take issue with the novel's so-called "Maoriness." The bone people had been awarded the 1984 Pegasus prize, an honour designated for Maori novelists. According to Stead the very existence 
of an "affirmative action" fiction award for Maori is unnecessary, given the success of Maori novels in general (180). Stead contends that a Maori literary award should be given to a novel in the Maori language, and to a work in an oral form such as poetry or song (a notion that appears to effectively ban Maori writers from the novel). Stead also maintains that Hulme did not have a high enough blood-quantum to qualify as Maori, and that the novel's Maori references were not authentic enough. Hulme's inclusion of Maori language and mythology struck Stead as "willed, self-conscious, not inevitable, not entirely authentic" (180). He questions the imagined and articulated world of the novel and its characters, finding they do not live up to a Maori ideal because of their European borrowings: "In fact Kerewin strikes me as more Irish than Maori” (182). But in the end he is disturbed by a darkness he perceives as having "something black and negative deeply ingrained in its imaginative fabric" (183).

What is interesting about Stead's statements is that they are unashamedly personal. With the phrase "strikes me" (used twice) Stead casts off his own critical authenticity, leaving himself open to question in a perhaps deliberate way. Stead applies a set of labels to Hulme with the implication she must live up to them, but he does so in an uncertain manner.

In 1989 Margery Fee challenged Stead's assumed criteria for indigeneity in "Who Can Write As Other?" She lists the many and varied ways in which indigenous people live - in cities, without their language - and cites well-known causes for loss of culture such as legislation against language and cultural practice (242-243). Fee makes the point that a recipe for a perceived authenticity "denies Fourth World writers a living, changing culture" (243). She charts the complicated territory of what is authentic, citing 
Said's view of Conrad's vision of a West-dominated Africa. Fee finds "a discourse [that] is possessed entirely by the coloniser" (244). She concludes that Hulme negotiates the limitations and possibilities of place and culture to "write herself into a Maori" and to write "New Zealand into Aotearoa" (245). (This point might prompt one to ask, was Hulme not already Maori?)

Stead was not the only critic reacting to Hulme's "minority" status. In a whistle-stop tour of neocolonial writing in The Post-Colonial Studies Reader, W. J. T. Mitchell is amazed that a writer requiring so many cultural indicators could have success in Britain: "When Keri Hulme, a Maori-Scottish feminist mystic from the remote west coast of New Zealand's south island, wins Britain's most prestigious literary prize with her first novel, we know that familiar cultural maps are being redrawn" (476).

Searching for influences, Ken Arvidson in an essay on contemporary Maori writing in Dirty Silence finds passages in the bone people that describe the mauri as being reminiscent of medieval English romance, for both its magical and spiritual content, and for its "heightened" language (124). Arvidson suggests that the purpose of such floweriness - a quality he also sees in Ihimaera -is to uphold "the survival of Maori spirituality and to stress its difference from the Judaeo-Christian tradition" (125). He sees a conundrum in the bone people, whereby the borrowing of a heightened English idiom that has romantic associations is being used to assert a Maori spiritual world to readers who might otherwise doubt its existence, namely Pakeha. Inherent in Arvidson's argument is, who is Hulme writing for? - a question many Pakeha critics seemed to be pondering. 
Five years after the initial publication of Stead's "Bookered" essay, Mark Williams joined in the argument, with a more complex view, in his essay "Keri Hulme and Negative Capability." Williams begins by usefully contextualising the bone people in terms of the political and economic world it was born into; a liberal-seeming Labour government (a party that for fifty years had attracted the Maori vote) was anti-nuclear and nationalistic, while at the same time privatising the country's assets and services (84-85). ${ }^{7}$ William's portrayal of the confident, even self-involved Aotearoa that the bone people came into suggests that the book might not have such a rapturous reception today, but that at the time the novel "announced the end of cultural cringe in New Zealand" (86). Identity issues were central to the novel's concerns. Here was a novel

stitched together out of the scraps and shards and flotsam and jetsam of literature that had washed up on the New Zealand shores from everywhere imaginable[with] echoes of Tolkein, C.S. Lewis, Melville, Sufi poets, Virginia Woolf, Lawrence Durrell, Edward Lear, Joyce, and Yeats. (86)

Williams seems to be recognising the ingredients for the "dirty silence" Bill Manhire later attributed to New Zealand poets (1991 151).

Williams' bone of contention, however, is with the manner in which the bone people's intertextuality places a psychological realism cheek-by-jowl with myth. Hulme is attempting, according to Williams, to make the reader accept myth as realism, to suspend their belief in the manner of Keats' "negative capability." Hulme's "mythic method" is a policy Williams sees as weakening the novel's obvious mimetic powers and romanticising the narrative outcome (104). On one hand Williams cites Hulme as intertwining literature and myth from outside traditional Maori culture to create a 
fictitious world, indeed, that the primary sources for some of the Maori material may have come from Pakeha, such as the historian Elsdon Best (99); and on the other he criticises her for a perceived ignoring of non- Maori sources in her attempt. "The problem here is that, for Maori and Pakeha alike, the pre-European world can only be recovered in terms of the intervening century and a half of European presence" (98). What Williams seems to be suggesting that a Maori story has no business taking up with the modernist novel.

Like Stead, Williams notes a distasteful darkness in the novel (Hulme condones, he argues, child abuse), bringing to mind Bhabha's observation that "the dazzling light of literature sheds only areas of darkness" (149).

Alongside assertions of a lack of authenticity in the novel, a host of critics have hailed the bone people as putting forward a model for biculturalism; a hopeful blueprint for future peaceful and fruitful coexistence between Maori and Pakeha. The latter debate has perhaps been more vigorous because of the former. Although "the future" has been arriving continuously since the novel's publication twenty-four years ago, biculturalism still appears to be noted in current literature surrounding the bone people. Sightings of biculturalism in the novel have come exclusively from Pakeha, and tend to argue for a vision of a level playing field between Maori and Pakeha, culturally and politically. Christine Hamelin, for instance, suggests that, "[g]iven the novel's resistance to absolutes, it should not perhaps be labeled Maori or Pakeha" (110).

One gets the sense in the many bicultural assessments of the novel that there is a strong Pakeha desire for a meaningful connection between, not just Maori and the 
Crown (in a political arena), but between Maori and Pakeha on a cultural footing. This notion raises the issue of the ambiguity of the term "biculturalism," which is essentially a political model, but has an obvious overflow into "culture." At times readings of the bone people as a bicultural document verge on relegating Hulme to the position of an Uncle Tom. While it is notable that there do not appear to be any Maori critics holding up the bone people as a model for biculturalism, bicultural readings display important signals for how the novel was and is received.

Janet Wilson in "The Abject and the Sublime" sees the bone people as contributing, along with writings of Curnow and Frame, to a national "coming-into-being" through language evolution. These three writers, according to Wilson, have rejected the parentchild colonial model in favour of an "evolving national subjectivity" (300). In the character of Simon Wilson identifies the disruptive power of the abject. Simon is flotsam; a cast-off, wounded, destitute, pre-gendered. Drawing on models of Kristeva and Lacan, Wilson argues for this quasi-state acting as an agent of change in the bone people; Simon as the Pakeha abject - "the very embodiment of the abject" - turns the colonial model upside down, a disruption in itself (312). But it is what the presence of the abject engenders among all three characters that interests Wilson. The abjectrootless, helpless, undefined - is able to traverse the territory between humanity and wilderness, between the spoken and silent, and, as a consequence of these journeyings, to break down and "scavenge" colonial structures for their new possibilities (311).

Wilson notes that the site of this organic renewal in the novel is often the shoreline (308). This constantly renegotiated space is "the principal zone of abjection," the door 
between knowing and unknowing, between the conscious and the unconscious. Certainly much of the novel's action takes place at the shoreline, which Hulme herself has described as being populated by the two characters "the actual land" and "the actual sea" ("Reconsidering the bone people" 140). This shifting shoreline is arguably an atonal space, where nothing is permanently central and everything is fluid.

Wilson's discussion of the shoreline, written in 1998, appears to prefigure the present point in time, when the issue of ownership and guardianship of the shoreline of Aotearoa is being revisited in the political arena. This contemporary political development waters down slightly Wilson's (and others) assertion that the bone people's fusion of Maori and European language and myth lend "a promise of hope for a bicultural future"(314); also that the power of the abject to unhinge "inevitably locates the modernist European literary traditions within a bicultural subjectivity"(315).

In the end, Wilson's assertion that the bone people contributes to a national comingof-age seems valid, given the novel's recasting of the tributaries of language that have "ended up" on the shores of Aotearoa; but can the delta of Hulme can be counted as a national landmark? It is possible that Hulme's position, precisely because it engages the abject, bypasses the notion of nationhood.

Joe comes to the fore in Codrina Cozma's study of that character as "model of cultural hybridity." Joe, it appears, of all the characters traverses the greatest narrative arc, going from an abuser of low status and self-regard to the guardian of the mauri ora (life spirit), a task he is ascribed by the prophet, Mira. Cozma reads a model of juxtaposed cultures in Joe's story, even though his narrative appears to head solidly 
towards the Maori. According to Cozma, Joe's "hybridisation" (his name, his job, his association with the Pakeha Simon) does not stop him achieving a sense of "authentic selfhood" (79). He is able to be bicultural and authentically Maori.

Cozma maintains some fairly blunt-edged notions of ethnicity and of the novel. Hulme, despite being Maori “does not[...]unthinkingly dismiss everything European" (69). (On the contrary!) But her bicultural reading of the novel is, once again, illuminating.

Twenty years on from the publication of the bone people, a new flurry of reactions both personal and critical emerged. In "Myths of Belonging" Sarah Shieff reads bicultural intentions in the novel:

[The bone people's] version of Maoritanga becomes part of a new myth for Pakeha agency, enabling a sense of spiritual connection with place based on an intuitive and sympathetic identification with notionally Maori understandings of place, being and belonging. (57)

Shieff cites, among other things, Christian motifs as proof of European influence.

It seems the bone people's enveloping of originally-Pakeha cultural belief and practice inspires Pakeha to question the boundary between Maori/Pakeha, and to insert themselves into the narrative.

Two Pakeha critics approach the issue of biculturalism in the bone people in a wider context, and come up with Maori-orientated visions for the novel.

Otto Heim reacts, as a jumping-off point, to William's notion of the disconnection between realism and myth. Heim sees Hulme's intertextual voice as a binding force that 
fuses the Pakeha literary canon with Maori English, bringing together the disparate worlds of realism and myth (56). While Heim sees Hulme's renegotiation of sign and language as raising the issue of biculturalism (her "ambivalence towards metonymic and metaphorical modes of writing takes on a tactical value in the politics of biculturalism") he concludes that the novel's internal discussion arrives at a Maori identity within a bicultural context (106). According to Heim, the cultural to-ing and fro-ing of the text is the very mode by which Hulme forms a "specifically Maori subjectivity" (107).

Rod Edmond's 1993 essay "No Country for Towers" deals with the interface between the perceived psychological realism of the bone people and the text's resident myths, taking as its locus the Yeatsian tower that Kerewin lives in and prizes, but which she burns down near the end of the novel. Edmond suggests that the novel's theme of belonging (represented by the place-to-be that is the tower), an issue that was and perhaps still is pressing for some New Zealanders, appears to offer "succour and comfort to Pakeha culture" (279). Pakeha, he seems to be saying, are or were searching for a shared myth. Edmond disagrees with the accusation of sentimentality some previous critics have aimed at the bone people's use of traditional myth. Instead, Edmond argues for a re-imagining of creation myths, where the novel's contemporary tellings suggest, "a possible myth of rebirth" (280). Among these myths, Edmond likens the settler myth of shipwreck and colonisation (Simon was shipwrecked and washed up on the shores of Aotearoa) to The Tempest, and to Robinson Crusoe turned on its head; in the bone people the "native" (Kerewin) rather than the incomer finds a 
sign of the new arrival, in Simon's sandal (280). Edmond also sees signs of a retelling of the Maui myth, where Simon is fished up from the sea.

Edmond's myth-identifying leads him to view the novel as Maori-centred. When healing occurs for each of the characters at the end, argues Edmond, Hulme creates "a full-blown myth of rebirth," focusing only on Maori myth (Edmond 283). Myths from outside Maori culture gathered earlier in the novel are assimilated, according to Edmond, to specifically Polynesian myths, notably those of the waka and the mauri. In the end, Aotearoa is "no country for towers. In place of the tower, aloof and isolated above the land, we have the modern meeting house spreading across it" (284).

Many of the above readings focus on Hulme's perceived borrowings as evidence for the novel's alleged political and cultural intent effect. It is worth nothing here Greg Dening's model for cultural continuity. Refuting the notion of borrowing, Dening argues for the idea of a continuum of culture before, during and post colonization: "In cultural changes of the encounter, beliefs, objects, words are not "borrowed" from one culture to another. They are transformed, re-created" (209).

\section{d) Tribal realism}

Having surveyed readings of the bone people, it may now be useful to briefly widen the angle and consider the views of three theorists writing on the subjects of authenticity, indigeneity and literature. 
Perhaps the most relevant argument for this thesis is Albert Wendt's vision for Pacific creative arts, articulated in his seminal 1976 essay, "Towards a New Oceania." Wendt argues against the notion of cultural purity, and towards the re-imagining of traditional and contemporary cultural icons, values and practices. Polynesia, according to Wendt, is not simply a series of communities stopped in time by colonisation, but peoples who continue, as ever, their evolution of culture: "No national culture is homogenous. Contact with papalangi and Asian cultures[...]has increased the number of sub-cultures or lifestyles in our cultures" (54). This inclusive interpretation of cultural authenticity is an exact fit with the manner in which the bone people places itself firmly on a cultural path that is both traditional and contemporary. The novel uses a blend of sub-cultures and lifestyles; characters in the bone people are wealthy and poor, they are isolated and communal, they are loving and hateful, they engage with both the practical and the supernatural; lastly, music is both tonal and atonal. The use of music in the bone people is deeply emblematic of its own inclusive process.

In his seminal work on East-West cultural relations, Orientalism, Said addresses issues of point-of-view and assumptions of power, which are worth looking at in relation to critics' reactions to the bone people. Orientalism, according to Said, is a political manifesto imposed by the "West" on the "East," with an assumption of the latter's weakness in operation (204). The hegemonic view of the weaker Orient is held by the "Orientalist." Said's work documents the history of this power relationship. When Said considers literature against this model, he sees a ruffling of the Orientalist's normally pre-emptive position. Writing of the unsettling influence of Arab poets on the 
Occident, Said attributes their work with "effectively disrupt[ing] the various patterns (images, clichés, abstractions) by which the Orient is represented" (291).

Said's portrait of the Orientalist certainly seems to apply to Pakeha critics who have applied European and arguably prescriptive readings to the bone people: both those who have seen the novel as "bicultural" and those who have judged it "not Maori enough." That Pakeha critics have been so eager to read and comment on the bone people (including this writer) attests, perhaps, to its disruptive influence. Different views are arguably brought up against each other on the common ground - the readable text - that is the novel.

Where Said spends at least some time inhabiting the view of the Orientalist, Elizabeth Cook-Lynn looks at First Nation writing from within. In "Intellectualism and the New Indian Story," she raises three issues useful to this discussion. The first is a general comment on the importance of jurisdiction over the Indian narrative - how Indian stories are given and received, how they are nourished, and what their consequences are. Secondly she draws attention to the proliferation of Native American literature that is published and read under the umbrella of life writing, or what she terms "tribal realism." Cook-Lynn notes that biography is a European genre, but her more strenuous objection to this slanting is that it encourages a superfluity of ethnographic readings of Native American literature. It is notable that the bone people has often been associated with its author and read as "autobiography." Hulme herself, seeing superficial connections between herself and her character as inconsequential, has expressed regret that she gave, when young, her main character a name that was "a 
really neat pun" on her own (1994 137) because it engendered a lack of reader distance. Further, readings of the bone people as "real" are arguably behind attempts to make it into a political manifesto, and to accept its myth as "the truth." Finally, Cook-Lynn argues against discussions like this thesis, and makes a plea for indigenous Americans to wrest criticism back from the clutches of white universities and reclaim "the tribally specific literary traditions by which we have always judged the imagination" (137).

Biculturalism may or may not be a viable political model for the future of Aotearoa, but it does not appear to exist as any kind of manifesto in the bone people. Perhaps the sightings of biculturalism - like rare birds seen flitting in the bush - are more a reflection of a Pakeha hope that, in the first instance, we will see ourselves in this extraordinary novel; and if we do not, we will insert ourselves. The bone people has arguably generated a new Pakeha myth outside itself.

\section{e) Open door, doorstop}

Hulme's own view of the bone people's place in Maori literature reveals an inclusive vision of creativity and culture. She does not, she asserts, hold with "distinctions between different kinds of writing. There aren't those distinctions in the Maori language, so I feel inclined just to ignore them" (O'Brien 25). In an interview with Harry Ricketts conducted before the Booker win, Hulme attends to this notion of dissolving boundaries between language usages by citing the work of Hone Tuwhare who, according to Hulme, "cock[s] a bawdy snook" and is an "Elizabethan Maori. His 
English echoes Shakespeare and the Bible" (28). Hulme seems to be making a plea for the possibility of a Maori voice that takes on Pakeha literature and language as part of its own texture.

If Hulme is breaking down the idea of linguistic boundaries, she is also amplifying the notion further into culture. Recognizes no literary scene, Maori or Pakeha, Hulme wonders where the edges of art can be found: "I don't know any Maori writer who isn't also involved with other so-called artistic endeavours" (Ricketts 29). (My emphasis.) At the same time, she maintains that having a Maori audience is "the best thing of all" (24). Hulme's view appears to be of a synesthetic relationship between language and culture that expands into identity, but also contains itself within an identity that is Maori.

In an interview with Sandi Hall in Broadsheet, again conducted before the Booker win, Hulme reports that, at a certain point in the rejection process of the novel, she planned to set the manuscript in resin: "[...]I still have, sitting there in the cupboard as an awful warning five cans of embedding resin which was enough to swallow the manuscript" (21). Although the resin death was averted by the intervention of Spiral, the transcendent image Hulme conjours up with her book-brick is one of a door propped open to the elements, to passers-by, to languages, to culture, to come-whatmay. 


\title{
Chapter 3: Music in the bone people's Narrative
}

\author{
So when the last and dreadful hour \\ This crumbling Pageant shall devour, \\ The trumpet shall be heard on high, \\ The dead shall live, the Living die, \\ And musick shall untune the sky!
}

\author{
John Dryden
}

\section{a) Synopsis and dramatic turning points}

Before discussing the function of music in the narrative of the bone people, it will be useful to outline the bones of the story.

Kerewin Holmes is a self-confessed hermit and neuter, living estranged from her original family but surrounded by her collections of possessions in a self-built tower at Moerangi on a remote coast of Aotearoa. She is Maori, has material wealth through a lottery, and is a visual artist with "drawer's block." Enter Simon, a silent, wizened tenyear-old Pakeha boy with kleptomania, followed closely by his foster-father, Joe Gillayley (also Maori). Joe's wife and biological child have died from the flu. Although Kerewin tries to maintain her splendid isolation in the face of Simon, Joe and the members of their extended family, she finds herself intrigued by their company. By the time she finds out that Joe is physically abusing Simon to a terrible extent, she is emotionally drawn in. Alerting authorities does not seem like an option, and she keeps the terrible secret.

As the three characters eat, drink and talk together, the climate is euphoric and tense by turn. While they are staying at holiday baches belonging to the Holmes whanau, 
Kerewin confronts Joe about the abuse and gets him to agree that in future he will talk to Kerewin when he feels out of control. Joe goes along with this because he hopes for a sexual relationship between himself and Kerewin, and for the three of them to be a perfect little family. Kerewin runs hot and cold, warring internally about her dangerous closeness to both Joe and Simon, and her silence about the abuse. Kerewin recognises that although there are real issues that spark Joe's anger (Simon's stealing, and his visits to the paedophile Binny Daniels where he earns a dollar for a kiss) Simon has learnt a self-destructive equation of inciting Joe to violence in order to gain his remorse and affection. Things get further complicated when Kerewin discovers that Joe's extended family (the Tainuis) know about Joe's violence. They do not approve, but nor do they act to stop it. What's more, they imagine Kerewin and Joe will soon be a couple. Kerewin publicly distances herself from Joe and aligns herself with Simon by singing songs for the boy in the pub.

On a visit to Binny Daniels, Simon finds him dead, fallen on a broken bottle. Traumatised by this, Simon visits Kerewin at her tower. But Kerewin has discovered the loss of her prized knife, stolen by Simon earlier, and is angry. She lashes out physically at Simon who, when he tries to hit her back, smashes her guitar instead. Later Kerewin rejects Simon verbally over the phone. Joe is enraged that Simon has ruined (he imagines) his relationship with Kerewin, and he beats the boy almost to death. During the beating, Simon lacerates Joe's stomach with a shard he has taken from Binny Daniel's broken bottle.

In a black aftermath, Kerewin destroys her tower and leaves Moerangi, only to be diagnosed with cancer. She holes up in a hut on her own to recover. Simon, 
permanently damaged by the beating, is put unhappily into hospital care. Joe does time in jail. On his release he is at his lowest point, aimless and full of remorse. It is then he meets a kaumatua who recognises his potential for renewal and entrusts him with the care of the Mauri, or life spirit of the place. Kerewin, recovered from cancer, rekindles her visual art, which has been her ambition all along. She has the wild idea of establishing a new marae on the site of "the Maori hall," which she does (431).

A year later, Kerewin has initiated the rebuilding of the marae. Joe returns, and invites Kerewin's family, who are reunited happily with her. Meantime, Kerewin employs a diver to recover Simon's parents' boat from the ocean floor. He finds three million dollars worth of heroin and Simon's developmental problems are made clear. Simon is allowed back home, and the three of them - Kerewin, Simon and Joe - are reunited. This time, they are not living in isolation but as part of a community and the outlook seems hopeful.

If broken up according to events that change the course of the story, the bone people subscribes to the Greek five-act dramatic structure. Its resemblance to the Greek model, and the fact that its narrative changes are so distinctly drawn and run independently of chapter headings, lend the novel to a dramatic reading - at least in terms of narrative. The bone people is a document that attempts, in more ways than one, to break the conventions of its own medium. In Image/Music/Text Barthes calls on Diderot to suggest the inter-relatedness of all artistic representation; that the pictorial, the theatrical and the literary are all constructed series of cut-out segments (70). ${ }^{8}$ 
Reading the bone people as five-act structure, then, reveals that each "act" sets up a set of circumstances, then swivels on a dramatic turning point into the subsequent act. The narrative span is large-scale; a lot happens in a long time, with emphasis rather on the psychological development of characters achieved through the tossing backwards and forwards of voice and point-of-view. The slow-stalking turning points create big shifts which encourage the reader to wonder what the characters will do next.

Because the acts and turning points are not on the beat with chapter headings, a syncopated rhythm sweeps across the whole novel.

\section{Acts and Turning Points:}

I. Kerewin is introduced as a loner and struggling artist who encounters Simon in her tower. The turning point is when she meets Joe and finds a friend in him. Now her carefully constructed world has been infiltrated by human contact (63).

II. Kerewin is enjoying having Simon and Joe in her life. The turning point is when she finds out that Joe is physically abusing Simon (146).

III. Kerewin is conflicted about her friendship with Joe and her responsibility to Simon. The turning point is when Kerewin tells Joe she knows about the abuse (189).

IV. As Kerewin tries to be a buffer between Joe and Simon, the three become even closer. Under pressure to enter a sexual relationship with Joe, Kerewin rejects first Joe, then Simon. The turning point is when Joe blames Simon for the rejection and nearly kills him (308).

V. The three characters are separated and go through healing. Epilogue: They are reunited at the new marae Kerewin has established. 
Musical references support this narrative structural framework, becoming part of cause and effect in the story; in addition, musical references flesh out character to help drive the narrative. In serving this function, music in the bone people makes a journey away from tonality towards atonality, and returns again to tonality. This model inverts the musical "index" Melnick ascribes to the use of destabilizing dissonance in modernist novels (126). Where, according to Melnick, dissonance re-imagines a free world in the face of authoritarian order, atonality spans widely to seek order in the midst of cultural, political and personal chaos.

At the novel's centre is the fact of violence, and that, as noted above, is where music isn't. Silence, its seems, is to play a part in an ambivalent dialogue between the characters and their most problematic concerns.

b) The failed woman artist as entree to musical motif

Despite the fact that almost every time Kerewin plays her guitar she and her instrument are beset by sonic mishaps - chords and melody buzzed out by rain, phones and moods she does not give up playing until everything has fallen apart in the fifth act. Why does she not simply prepare another transforming round of shellfish (her cooking is always splendid), rather than persisting with the spooked guitar? Why, more pertinently, does Hulme put her character through the frustration of getting it wrong? The question seems to be bound up with Hulme's approach to two iconic fictional character types: one, the musician, and two, the woman artist. 
There are many examples of musicians as characters in the modern realist novel. $\underline{\text { An }}$ Equal Music by Vikram Seth concerns a member of a string quartet and his anxious relationship with his musician girlfriend. In Ian McEwan's novel, Amsterdam (another Booker Prize winner), a composer is forced to face mortality and love when a friend dies. In Ann Patchett's Bel Canto an opera singer is one of a party besieged in a house by political activists, and under these confined conditions love flourishes. Roddy Doyle's The Commitments is a comic novel about love and the blues in working class Ireland. Louise Erdrich's The Master Butcher's Singing Club tells a generational fable in which butchery, music and passion go side by side. The New Orleans jazz musician in Michael Ondaatje's Coming Through Slaughter goes mad for the love of two women. The Ground Beneath Her Feet, by Salman Rushdie (which became a song of the same name, performed by $\mathrm{U} 2$, with lyrics by Rushdie), combines unrequited love with a history of

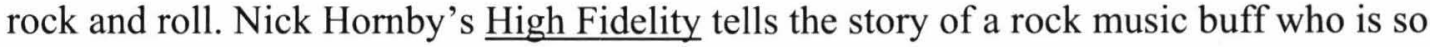
cool he almost lets love slip through his fingers. These novels deal directly with musicians, music-lovers and music, and so the practicalities of playing music are part of the narrative engine. The works listed here have male musician protagonists, apart from Bel Canto (and in that novel the diva fits into the stereotypical role of the interpreter of music, the beautiful mouthpiece). Without exception, they are primarily about love, where music serves as an Hitchcockian McGuffin, the "object" around which the plot swings, which may or may not be very important in itself. In all of these novels, events happen because of music, but equally they could happen because of something else. Music is employed as narrative bread and butter; it may or may not be part of the symbolic and verbal arrangement of the novel. 
In Joyce's Portrait of the Artist as a Young Man the young protagonist encounters a world that both sabotages and makes necessary his quest to be an artist, but in all events his ability to be an artist is not under threat. By the same token, Proust's fictional writer in Remembrance of Things Past might find the world troublesome, but art is the untroubled solution.

It seems that in the above list the characters whose art is arbitrary to the story are musicians, while the artists whose work is embedded thematically are writers. Perhaps it has something to do with the nature of music being a different medium and writing being the text. The bone people, however, in contrast to both these models, sets up Kerewin as an artist failed by visual art, but to whom music happens by accident. Kerewin is not a musician, yet there is music in her life and it effects change in the episodes of the story. The bone people is arguably not about Kerewin's personal music, but about the unseen, metaphorical, even spiritual power of music to destroy and heal. Further, the bone people is about love, but not erotic love and coupledom. Rather, Kerewin wants friendship, acceptance and community love. The two themes, music and love, stalk side-by-side through the novel, and are approached similarly, in terms of the large-scale, behind-the-scenes havoc they can wreak, and the positive changes they can achieve.

The second type of fictional character I am concerned with here is the woman artist, a role that ironically appears to have acquired the status of a traditional one; although women outside the covers of novels may struggle even today for artistic autonomy, the literary artist has become something of an icon. Kerewin Holmes, a self-proclaimed visual artist (who tries "to catch the spider shadow of the morning's dreaming[...]" [71]) 
joins the other high-modernist female literary protagonists who have put their trust in art as if it were some kind of god, the way Jane Austen's characters negotiated the whims of the marriage market, and Jane Eyre relied on Fate. Janet Frame bestows artistic inclinations on several of her main characters - Istina Mavet, the retired art teacher in $\underline{\mathrm{A}}$

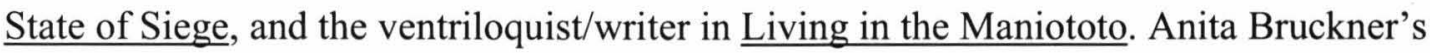
Edith, of Hotel du Lac, is one of several of Bruckner's characters who are journeying writers, single women who use their pens to buy themselves freedom to wander and think. Even poor old Esther Greenwood of the The Bell Jar has writerly ambitions. Because they are artists, these characters inherit a set of ways that we associate with artists' negotiations with the world - interpretative, metaphorical, challenging, and allowing the subconscious. They are also characters who live in a world of privilege. Susan Ash, writing on Frame (arguably the slightly uptight Pakeha fairy-godmother of Hulme), credits The Carpathians with challenging the postmodern rejection of personal identity. Women, according to Ash, "have never been in possession of that full, 'authentic,' self-constructed identity[...] The place of the woman artist who writes, paints, plays her way towards a self-identity that has been denied her." (125).

There are two differences between the Framian model of the woman artist, and Kerewin. Frame's characters are absolved from the necessity of taking part in "the world" - that is, community, work, children, indeed love. They are allocated other-worldliness and their quest is to attain the state of the artist unequivocally. Kerewin, on the other hand, is destined to create and live in a world that encompasses not only her art but the emotional and physical highs and lows that come from being close to other people. Hulme also overturns any expectation the reader might have of the woman artist by 
allocating the traditional woman's role of caregiver to a distinctly untraditional character. This undercuts the notion of the woman artist occupying a place of privilege.

But the most confounding factor in her characterisation is that Kerewin is not just a woman artist, she is a failed woman artist. While Kerewin was "busy blessing the god of munificence, the lightening came. It blasted my family, and it blasted my painting talent." (28). Many times Kerewin tries to paint or draw, but she is disgusted with the result.

Kerewin, then, is set up as an anomaly - a visual artist whose job, we might assume, is to attend to her singular vision of the world, but who has constructed an hermetically sealed space in which "nothing happens." What Hulme does for her character is to leave the door open on an artistic, interpretative, world; because in the meantime, art knows best. Kerewin's failed attempts at music, which do not disturb her nearly as much as her botched attempts at visual art because she does not set out to be a musician, are agents of change in the novel. Art will come in the back door, through music. Hulme's woman challenges the very notion of the woman artist and inverts it. Hulme, then, is taking on more than perceived notions of "womanhood" as her ideological opponent. She undoes the image of the woman artist as privileged, successful and free by backing her character up against a wall, where her visual art is taken away. The subconscious realm of art, even the archetypal substructure of art, takes its place. It is music. Knapp writing on Sartre's Nausea, calls this the "reasonless, timeless, dimensionless space" in which the undone character Roquetin can proclaim, "I am in the Music" (139).

Like Roquetin, Kerewin is an artistic character down on her luck, and therefore intuitively able to open the door onto. Simon's dual space of silence and music, which in turn becomes part of the main narrative thread in the novel. 
Discussing Balzac's short story "Gambara," in which the protagonist is emotionally and psychologically consumed by music, Knapp describes the artist's muse as an attempt for the artist to find perfection in the unconscious (38). Music leads Gambara to the continual worship of his female muse or anima, Marianna, the "abstract personification of the feminine principle" (39). In a startling twist on this Platonic model, Hulme eschews the convention of the muse as imagined lover and instead has Kerewin attempt to find perfection in both the concrete and the artistic world, through her collections and through her artistic life respectively. The latter sees Kerewin searching for self-expression in her drawing, and for harmony in music; by these means she enters the volatile world of the muse. Like Odysseus Kerewin follows her desires, but into her own underworld, and it is there that her adventures begin. Like Odysseus and Gambara, it is in the dangerous and changing world of the muse that Kerewin is brought into an existence where her own inner world can reside alongside everything and everyone that is outside herself.

Perhaps the simplest element in Kerewin's music, her guitar-playing, is also the most laden with possibility. According to Barthes there are "two musics," one you listen to, and one you play. The latter involves the body and the senses, and can be "tremendous" (149). In attributing her the willingness to play the guitar, no matter what the outcome, Hulme calls on Kerewin to go after the tremendous. 


\section{c) Music in the bone people's narrative}

The John Dryden verse quoted at the beginning of this chapter describes what is happening in a dramatic sense in the bone people; music is involved in dramatic undoing in the story. While Kerewin (and her guitar) as a character is open and alive to music, Simon is the agent of change in the narrative that activates Kerewin as a receptor. At points of narrative change, music generated by both Kerewin and Simon have the effect of pushing ahead the events of the story. At these points, music is summoned (to call on Knapp's interpretation of "synesthesia") to be of use as an abstraction outside its "usual habitat"(82). Furthermore, the abstracted music referred to in the text is removed from its expected harmonic home.

Simon's sound-world is introduced right at the beginning of the novel, in the first three lines of the prologue "The End At The Beginning":

He walks down the street. The asphalt reels by him.

It is all silence.

The silence is music.

$\mathrm{He}$ is the singer. (3)

Contained in these lines are emblems of what is to come: Simon's inner world of silence which he fills with his own self-directed music, and which will be the means he uses to "get at" Kerewin; also present is the synesthetic breaking down of barriers between the senses in art. In this opening passage, sound, sight and tactility are fused as the street, spooling out in front of Simon, appears to get up off the ground and become a "reel," a musical dance that is to be referred to again in the novel. In keeping with 
Pythagoras' Music of the Spheres - the idea that music resonates everywhere - the very pavement is musical.

By page 6 Hulme has introduced the idea of disruption of harmony, which is to be an important metaphor for both the thematic vision of the novel (the personal and societal disharmony of the characters) and its narrative function (what happens): "In the beginning it was a tension, an element of strain that grew and crept like a thin worm through the harmony of their embrace."

The novel's numerous "found sounds" are also introduced early. On page 13, where "Intermittent wheeping flutes from oystercatchers," wheeping in its archaic form refers to shedding or drooping as in a "wheeping" willow, and "flutes" is used as a verb to describe the drooping of a sound. This synesthetic equation of sound, sight and kinesis calls on a musical aesthetic to provide thickening narrative detail (what is, and what happens).

When Kerewin attempts conversation with the silent Simon, the first undermining of harmonic tonality occurs:

She takes her oldest guitar down from the wall, and picks a series of delicate harmonics to check the tuning. Then, the body of the guitar cuddled into her, she plays wandering chords and long pure notes and abrupt plucked melodies. rain. (25)

The music melds into the steady background white noise of the

Later in the scene, annoyed at Simon's sulky uncommunicativeness, she "launches into an ersatz flamenco rhythm," but the hissing of the rain once more drowns her out. In 
the next moment, the "radiophone buzzes" and this atonal noise heralds news of Joe, Simon's father, through the telephone operator.

Atonality, here represented as white noise, intrudes on the tonal environment. This intrusion implies that Simon's perceived silence is not really silence, and this will be proved again in the course of the novel as Simon puts in his oar of atonality, and Kerewin hears him.

At the turning point from act 1 into act 2, Kerewin has enjoyed an evening of food, conversation, chess and music with Joe and Simon, and looks forward to more, while still doubting her capacity for friendship: "Rich night. A promise of times to come... maybe" (63). This constitutes a change of gear in her solitary outlook. While Simon was the initial interloper, it has been Joe's company that has excited Kerewin. Joe is similarly excited by Kerewin. On the occasion of this first meal, he has come straight from work. He and Simon shower while Kerewin plays the guitar, but, as if they are sounding each other out slowly, the instrument's tonality is mysteriously beyond earshot: "In the bathroom, Joe can hear the guitar, the rhythm of it rather than the chords: the walls are too thick for more" (56). They play chess and Joe can feel "mind muscles long-unused” (60). At one point, Kerewin sings quietly, “ “Moonraker, sunraker, o wild song for my ruby guitar.' "Simon, watching the proceedings, remembers that Kerewin played the guitar for him when he first visited her and tries to read her music as some sort of indicator of her regard for him:

(SHE GOT RINGS. SHE PLAY THE GUITAR FOR ME) "She liked you?

NO.) (60) 
When Simon next visits Kerewin, he listens to her singing as she draws and has anxious thoughts about a vague past abuse and, once again, doubts about Kerewin's affection, which he craves. Reminding himself that he has the power to "store any sound he wants and duplicate it inwardly," Simon pitches himself into a reverie in which imagined music soothes him :

The only defence he could raise against the dark and the horror and the laughing terrible voices were his golden singers, the sounds and patterns of words from the past that he had fitted to his own web of music. They often broke apart, but he could always make them new. So he lay prone on the floor, and listened to them, and made Kerewin part of them, part of his heart. (73)

That Simon's internal music is a web summons a clear visual image; an array of notes with no obvious centre, and therefore atonal. Into this atonal inner world Simon inserts Kerewin. Kerewin has no idea she has been so honoured, but as she continues to draw "the hours sing by" (74).

It is worth noting that before Simon enters his web reverie, a fly drones past, summoning once again the raw material, noise; the ambiguous place from which all sound and all music will come (73).

As the act proceeds, the three characters go to and fro on visits, performing a slow getting-to-know-you dance around each other, and the subject of Simon's strange music is raised. A contraption Kerewin has made from a crystal spinning between two magnets reminds Joe of the structures Simon makes: "Things he reckons make music" (102). Kerewin recounts that Simon asked her to listen to one of his self-made 
structures of marramgrass, shells, driftwood and seaweed, and that she had lain down on the sand and heard her own pulse, the wind and the sea, combined to make music. Joe recalls doing the same once, but maintains he had heard nothing apart from "a sound of darkness that seemed to sing...” (103). The music had disturbed him so much he had never listened to it again, and had stopped Simon making the "music hutches" whenever he saw him doing it.

It is at this point that silence enters the equation on a deeply ambiguous level. Up until now, Simon's inability to talk appeared to occupy the "silent" space in the proceedings. Now, Joe's willed deafness allocates silence to him; he hears silence. Joe's world becomes more complex. As the perpetrator of violence against the Pakeha Simon, it is hard not to read his actions as anger against colonization. Joe, it seems, has personal love for the boy, and a systemic hatred, and these apparently conflicting states war within him. In fact, they are not so conflicted, as the social complexities of mixed race prove. But Joe, being deaf to the metaphysical (Simon's music) and atuned to the real world - his job, his whanau, the pub - is unable to resolve his ambiguous feelings.

Kerewin, who was herself deaf to Simon's music (and perhaps to her own), is now poised to enter a mysterious musical world where the unexpected and the ambiguous express themselves in the form of atonality. Barthes suggests that a certain kind of deafness (such as the deafness of Beethoven, during which he composed some of the most profound compositions of his oeuvre) can open the door on a "tangible intelligibility" (153). Barthes is talking about a music that is not reliant on the senses, is not reliant on conceptual elements, is not grasped by performing or listening, but by reading. From the first moment of hearing the music of Simon's hutches, Kerewin is 
attuned to its volatile tonality. In this space perhaps Kerewin will be able to "deal with" what Joe cannot - the impossible legacy of colonization.

Kerewin is about to find out about the abuse against Simon. He has helped himself to alcohol in her tower, and is drunk. His guard is down, as hers is often. The grisly discovery points the narrative into its third act. At the end of the "nightmare day" Kerewin takes down her golden guitar and tries to play Rossini's Overture to "The Thieving Magpie," but its tonality escapes her as "the ragged beginnings of a tune" dissolve into swooping, flying and gliding (150).

Interaction between the characters progresses on tenterhooks, with Kerewin's awful knowledge. She is reluctant to sever ties, and suggests a holiday at her whanau baches. It is here that Joe has a strange, silent musical occurrence. After the music hutch episode, his involvement with music has been nil, but now we learn that Joe plays the guitar too (a not-unlikely scenario for a Maori man). When he puts his and Kerewin's guitars side by side on the bunk in the bach, the gesture is suggestive of a sexual relationship between the pair of them (165). It is as if Joe's longing for Kerewin - and the undoubtedly simplifying factor of her being Maori - allows him to risk the uncertainties music might bring, but only silently. He does not actually play the instrument. However, where the musical transactions between Kerewin and Simon function to open up a view on each other's world and beyond, for Joe silence embeds him in reality. His violence comes back to greet him as Kerewin reveals to Joe that she knows about the beatings. There is no musical accompaniment; only a deafening silence. 
The event takes place on the first day of a holiday at the Holmes' whanau bach. As Kerewin, Joe and Simon walk on the beach, Simon, in a peevish mood, flings a slug at Kerewin. This starts a sequence of events in which Kerewin admits she feels violent towards Simon, "Even considering I know how much he gets whacked and all” (189). Joe is taken aback by this acknowledgement, and as Simon continues to antagonise him, he lashes out at the boy, only to be floored in a physical dust-up with Kerewin. The changed dynamic between them works as a turning point to catapult the story into its fourth act.

Later that evening, the air cleared and equilibrium restored, Kerewin and Joe prepare a meal and Kerewin explains that her prowess in fighting is due to the Aikido training she undertook in Japan. She keeps her notes in a guitar case (199). When she puts the book away, "the guitar strings hum faintly as the lid goes down" (200). Even though the sound is made by accident, the reader can "hear" the implied harmonic tonality; because of its tuning, the guitar when bumped will emit a thrum of mostly fifths. After the silence of the fight, and the ground it has shifted emotionally between the characters, the natural harmony of the spheres has inserted itself.

As if in retaliation, Simon - the musical interloper - has a revelation of consciousness about the fight. He recognises that he has incited violence so that there will be affection afterwards: "Get rid of the anger round the woman... stop the rift with blows, with pain, then pity, then repair, then good humour again. It works that way... it always did" (192). While this might seem a rather knowing strategy for a child to adopt, let alone articulate, it does address the issue of why Simon continues to love Joe despite his brutality. Simon is knowing beyond his years, and his character traits have 
all along indicated an inner logic. With his admission of inciting violence, we see clearly that he is willing to suffer pain to get love. In a telling incident of transference that occurs soon afterwards, Simon brings dead baby rabbits back to life by "feeding them music, underbreath singing" (203). The tune he summons "rings and swirls" in an approximation of his centreless, atonal web of music.

All through the fourth act, now with all the cards on the table (Kerewin knows about the violence and Joe knows she knows), music has a central role in shifts of narrative. Although it has been Joe who excited her in the beginning, now, living with the horrible secret, Kerewin aligns herself with Simon. Simon in turn allows his musical world to come to the surface. On Kerewin's part, her music strives for harmonic tonality, such as when she gently plays the "Marseillaise" to Simon (taking care not to "hurt him with words"), in an "arpeggio of harmonics" and "a series of brisk minor chords," but ends up "skating down a dozen frets" (223).

Simon's music, the intruding atonality, continues in its webby way. When Simon 
range of ecstatic reactions, including "Nothing! She heard me singing! But nothing!" and, “Icansing!Icansing!Icansing!” (237).

As the musical bystander, Joe is beginning to hear. He listens to Kerewin play angry, discordant guitar music, and interprets it as the gulf widening between them; but at the same time he recognises with pleasure that Simon is now, through Kerewin, "passionately, wholeheartedly, openly in love with music" (239). Discussing the change in Simon, Kerewin describes the boy's music as "wordless mouth music" while Joe proclaims, "Sweet Lord, it's tuneful. He really can sing" (240). Kerewin, it seems, picks up Simon's inner atonal web of music, while Joe hears harmonic tonality. Could it be that Simon's inner music is atonal, while his outer music, the music that can be heard by the world, is harmonic? Despite his approval of Simon's tune, however, Joe's theme of feeling left out continues and here he makes his baffled observation about Kerewin loud guitar music: "It's not blues, it's not rock, it's not folk or imitation electronic and sure as hell, it's not any Maori music he's heard before" (240-241). Joe is becoming untuned, and perhaps stands on the doorstep of the atonal space.

Joe's ambivalent position at this point is important for the novel, both narratologically and thematically. All along, Joe has differed from Kerewin in his interaction with the world. Where Kerewin has been able to secede socially and economically, Joe has faced the "real" world of work, whanau and parenting, a world that to date has not served him well. Joe is to shift his focus radically as he becomes the guardian of the mauri. His journey is far more polarized than Kerewin's or Simon's. At the point where Joe "hears" but cannot fathom what kind of music he has heard, he decides not to or is unable to enter the atonal space. Hulme, it appears, is playing 
devil's advocate and thumbing her nose at Kerewin's "so-called" art (Hulme int. by Ricketts 29). Joe is to travel an unmusical, dark path towards the mauri. In a sense the journey is not his own, but that of the mauri's search for a guardian. At its end, the focus of Joe's responsibilities in the "real" world are completely altered. His work, for instance, is never mentioned again, but it seems likely he would continue to do his manual job at the same time as looking after the mauri. ${ }^{9}$ Joe, in the end, lives a life that is recognisably real for contemporary Maori, within the vision of a Maori space. He lives a dual tonality.

Towards the end of the fourth act, singing is used to illuminate important action between all three characters. At an extended family gathering in the pub, Kerewin has discovered two things: the first is that the Tainuis know about Joe's violence towards Simon but do nothing about it, apart from admonishing Joe; the second is that the Tainuis are expecting Joe to marry Kerewin. In a reaction to both these scenarios, Kerewin borrows a guitar from the pub musician and sings two songs which stingingly communicate her rejection of Joe as a sexual partner (a continuation of their strange music/silence conversation) while at the same time staking her claim on Simon.

The first song is Simon's Mead Reel (294). Kerewin announces to the gathering that she has composed this song for Simon. On the surface, it is a wine song (like Hulme's poetry sequence "Winesongs" which appeared in $\underline{\text { Strands) }}$ ) but it seems also to allude to pain and addiction in general, and to Simon's co-dependent goading of Joe in particular. In this song, Kerewin (without Simon present) recognises the connection between her own addictive and destructive behaviour and Simon's. Once again, the 
song is an attempt at harmonic tonality, but is beset with atonal departures, the tune, “only just catching its balance" (294).

While Kerewin sings, Joe looks at her and muses on his desire to be her lover. In her next song, however, Kerewin reveals that she loves the boy dearly, but that her love for Joe is platonic. It is a song that sets out to be tonal, with chord sequences described "D A7 G" - but which keeps letting atonal sounds intrude: "jangles, seemingly mispicked" and "again the wandering eddy of discordancy" (295-96).

Events are thrown into the air in a replica of a web of music, as the turning point into the fifth and last act brings events to a head. Simon, having seen Binny Daniel's dead body, goes to Kerewin's for comfort, but she has coincidentally just discovered the loss of her prized knife and is angry to the point of violence. In a fight of near misses, Simon kicks in Kerewin's amber guitar, an action that is accompanied, of course, by an implied twanging (305). This is the ultimate atonal act; the releasing of the strings from their tuned home. The ensuing catalogue of angry rejections - Kerewin rejecting Simon, Joe feeling rejected, Joe rejecting Simon - ends with Joe's terrible final beating of Simon.

After Kerewin has realised her implication in the violence against Simon, she plays Ravel's "Pavane For a Dead Infanta" on the guitar (327). In a sudden departure from the atonal, this piece is starkly and purely tonal, adhering to simple harmonic chord progressions. Later, when Joe is in jail, he remembers this piece, "playing it so often in his mind that when he next picks up a guitar, his fingers settle into the melody without him meaning them to" (327). 
Kerewin leaves the tower, with only a suitcase and her Ibanez guitar. There is no mention of music for seventy-six pages; a grand silence, while Kerewin is ill, Joe is in jail, and Simon is in care. It is not until she begins to emerge from her solitary journey that music reappears. Then, she tries her singing voice out for size, and has a reflexive moment of considering the machinations of music-in-fiction:

\section{"Little febrile clots of words that choir in earfuls humping off the page." (418)}

With her dark night of the soul coming to an end, Kerewin strums and plucks "untunes" on the guitar, or "simply hold[s] it in weeping hands" (420). Yet when she lists the things she loves most in her life they are, "Very little. The earth. The stars. Cool classical guitar. Throbbing flamenco" (423). She begins practising scales on the guitar, signaling a newfound comfort with both harmonic tonality and its surprising other, “untunes" or atonality (427).

In the last episode, when all three characters and their extended families are brought together on the new marae Kerewin has rekindled from the ashes of the old "Maori hall," music exists in all shapes and forms. Kerewin marvels at herself "singing with the rest inside the tight sweet hall[...]" (432). There is an accordion, a guitar, a reedy song, the blaring of the young people's stereo and the reaction to it: "fuckthisracket" (441). The ubiquitous buzz crops up and Joe hears Kerewin's voice over it: “ 'Ah sheeit...' coming through a wall, over the buzzzz and jingle of music and talk[...]" (444). In this inclusive environment, varieties of tone, timbre and tonality exist side by side. "Noise and riot, peace and quiet, all is music in this sphere" (443). On the very 
last page of the novel, Kerewin sings a final song. It is Simon's mead reel, "a sly fastpicked tune," with nothing to disturb its harmonic tonality (445). In the end, atonal and tonal do not interfere with each other.

\section{d) Ringing changes}

All music in fiction is silent; it is only implied. Descriptions of music leap immediately towards the metaphoric (this point will be discussed in Chapter 4), but metaphor can function as a mirror of reality. The esoteric and sensual world of music in the bone people becomes, to quote Knapp, "thingified" for the purposes of the narrative as it summons realistic instances of music in the world around us and uses them to change characters' motivations and actions (140).

Music, then, can be seen to shape the turns of event in the bone people. An openness to music on the part of Kerewin invites the disruptive atonality of Simon to "white out" her carefully constructed solo existence. By association, this atonal interference connects Kerewin with Simon's non-musical but potentially more disruptive (because of the spectre of sexual intimacy) foster-father Joe. Kerewin's entrance into this musically and emotionally turbulent world of loss, need, love and violence is the factor that will change her vision and bring her back to a kind of home. While Kerewin deals with her ambivalence through the musical and mystical channels, Joe shuns the outlet of the atonal.

As noted above, the narrative of the bone people is simple. But at the same time it is grand, because the narrative sweep is inseparable from its symbolism and the manner in 
which it is told. Music, both tonal and atonal, are part of the imaginative world of its narrative. 


\title{
Chapter 4: Music as Symbol in the bone people
}

\author{
Sometimes I dream \\ my father is a guitar, \\ with a hole in his chest \\ where the music throbs \\ between my fingers.
}

Martín Espada

\section{a) The hills are alive}

The Rogers and Hammerstein musical, The Sound of Music, the film version of which famously starred Julie Andrews, could have been titled The Meaning of Music. Not only did the production entail singing, it explored themes summoned by the idea of music; soaring personal freedom, love, nationalist identity and the concept of home. Music in the context of the film can be seen to call on its enormous archetypal power as a shortcut to meaning. Writing about music in literature has an obvious limitation of lack of sound (where music described in or mimicked by words is a perhaps futile attempt to represent the esoteric) but the symbolic givens attached to music are just as accessible to the page. The structuralist notion of the metonymic in language, where words may make associations with other words through their symbolism (Eagleton 99), can also be applied to musical references in a text. Such a reference is inherently symbolic and capable of creating, without actual sound, the same bypass to meaning that occurred in The Sound of Music. 
Symbolism abounds in the bone people - Kerewin's tower stands in for her isolation, her collections build metaphorical walls around her (it is worth noting that Hulme's next book after the bone people, Lost Possessions, concerns the poetic diary of a writer who has lost everything), the three-person ersatz family calls upon the Christian model, and - not least - the associated meanings of music to invoke the reader's sense of "negative capability." In the same manner in which Hulme might encourage the reader to accept myth as reality, she asks us to accept words as not only the symbols of objects, actions and feelings, but of music and its own attendant meanings. Hulme calls on the paraphernalia of music (its objects, its instruments), on found music (existing compositions), and on an imagined array of sounds to manufacture a world of suspended belief.

The very idea of symbolism raises the issue of what meaning constitutes. Bahbha's Third Space is a useful model for thinking about how the bone people plays with ideas of meaning. The use of atonality in the novel appears to replace the imperative of harmonic tonality (which although grounded in nature is read as culture) with the notion of ambivalence. With this shifting state Hulme throws all perceptions of symbol up for renegotiation.

\section{b) Guitar woman}

Objects are very important in the bone people, firstly in a narrative sense, where Kerewin guards and talks about her collections, and where Simon steals and hoards. Secondly and importantly, these various collections do symbolic work in gathering 
outside meaning and metaphor into the orbit of the text. On Kerewin's part, her collections in general represent her psychic armour, and specifically (her pounamu, her pipes, her books, her knives) they illuminate her personal and cultural place. This partiality to things is not new, of course. The sacredness of objects is embedded in both Maori and Christian beliefs - even Anglicanism, which was the largest and most influential Christian mission among Maori had transferred a perceived vain reverence for icons to the jewels and accoutrements of its royalty (McLean 270). Kerewin's regard for special objects reflects a Maori spiritual and psychological investment in taonga. Not least among her possessions is her collection of guitars.

The instrument is laden with associations. There is a stereotype that every Maori gathering has a group of men playing guitars to accompany the singing of waiata and popular songs (such as “Ten Guitars”). Hulme inverts this masculinist expectation by making Kerewin the guitar player, not Joe. As noted in Chapter 3, this opens the way to narrative development. On a representational level it amplifies Kerewin's asexual orientation, and could imply a real or imagined ostracism from whanau; a guitarplaying Maori woman dangerously transgresses a gender boundary. In popular Pakeha post-war society, the guitar was raised to an iconic hallowed status through pop, rock and folk musicians. The cover of the Simon and Garfunkel album, Wednesday Morning, 3am, for example, on which Paul Simon plays a guitar on a subway station, emblemises the guitar's portable association with freedom. In the bone people, Hulme plays these associations, both Maori and Pakeha, to big effect. And, having set the instrument up as an icon, Hulme uses it conduct a dialogue between tonality and atonality. 
The colours of the guitars are specific. In the first instance, when confounded by Simon's unannounced arrival, Kerewin plays a golden guitar, suggesting a metallic jangliness which "sounds" like a random, jammed-together collection of notes (25). Throughout the novel Kerewin's guitars are variously "golden," "ambered," "ruby," until after the final beating, when she chooses a black guitar, suggesting a damping down of any sound-association altogether.

When Kerewin cuddles her guitar during that first encounter with Simon, she initiates a physical relationship with it that persists through the novel (25). Later in the same scene she "props" the guitar against herself, then "strokes its amber body." A telling incident occurs when Joe, who is in general outside the musical negotiations of the story, puts his own guitar and Kerewin's side-by-side on the top bunk of the bach (165). His choice of the top bunk suggests secrecy, but in any case, the idea of their bodies following suit is put aside soon afterwards when Kerewin reveals to Joe that she knows about his violence. She appears to be sending him a message later on when she when she refers to Aikido (as if to suggest to him a controlled release of violence), and takes down a guitar case that is a reliquary for her Aikido notes (199). Yet later, when Joe objects to Kerewin's brutal strumming, she puts the guitar "bellydown on her knees," a position potentially damaging to the fragile guitar and at the same time suggestive of a sexual vulnerability between herself and Joe (242). In another scene before going their separate ways, Kerewin asks Joe to pass her a guitar, and when he does so the action causes him to "grunt with pain" from the cut Simon has inflicted on him (324). Kerewin asks sympathetically if the wound is "fretting" him, at once inquiring after his physical condition and casting him into the image of a guitar. 
The most powerful exercising of the guitar as a symbol is when Simon, trying to fight Kerewin, kicks in one of her guitars by accident, but clearly as a stand-in for her body (305). At this crucial point, Hulme uses a restrained "hum" as the only aural effect, and the reader is left to imagine the many-noted, atonal jangle of the freed strings. The symbolism of the unstrung guitar cannot be underestimated: the tuned strings, which have been in Kerewin's arms for so much of the novel, are released not only from harmonic tonality but ultimately from any kind of music.

Kerewin is subsequently to abandon the guitar, sending her last one to her estranged family after the dispersal of herself, Simon and Joe (419). Without her new whanau, she has no need for the transformations of music. But as Kerewin emerges from her "underworld" of illness and despair, she buys a new guitar and strums it in the way Orpheus plucks his lyre, to illuminate her life. The constant upheaval of atonality appears to have subsided. On the very last page of the novel Kerewin has a guitar slung over her shoulder, but by this time the dramatic musical landscape of the instrument has done its work and when she plays, it is without incident (445).

\section{c) Music underground}

In 1951 John Cage, after spending time in an acoustically sealed chamber, devised his composition, 4' 33" (Four minutes, thirty-three seconds). Audiences sat in concert halls and listened to four minutes and thirty-three seconds of, not silence, but themselves breathing, their blood pumping, their neighbours' coughing and spluttering 
and rearranging themselves in their chairs; in other words they confronted the myth of silence. In the same way, Simon's silence simply uncovers buried or unheard sounds.

Early in the novel Simon's world is portrayed as silent, but that perception is soon shattered by his seeming agency of raw sound, when rain and buzzing intrude on Kerewin's guitar-playing (25). Later, Simon shares his apparently silent inner musical world with Kerewin (236). His scribbled words are, likewise, silent. Silence, then, which is patently under threat in the events of the novel, cranks up the musical engine of the story. Related to this notion, Simon's collected sounds in his web of music seem to come from the earth. He builds music hutches on the ground and must lie with his ear close to them, to hear what they collect. Simon's supposedly Celtic origins appear to be alluded to here. Vague myths of fairies as underground music-makers abound, according to Daniel F. Melia in "The Lughnasa Musician in Ireland and Scotland." Bad fairies used music to entice people into caves who never returned. Good fairies took unfortunates under their wing inside a mound and passed on extraordinary musical gifts (365). The fairies might make beautiful music, but unless you got close to the ground you would not hear it. Simon's diminutive stature and his scrambling gait would bring him in close proximity to "earth music." By contrast, the taller you were the less you heard - unless, like Kerewin, you took the trouble to listen.

By the same token, Barthes' analyses of deafness, outlined in Chapter 3, whereby "tangible intelligibility" opens up a character's (and a reader's) ability to "read" music, is present in the "silent" music of the bone people. That it is present in the found compositions attests to the symbolic inter-connectedness of the novel. 


\section{d) Reading the found compositions ${ }^{10}$}

While many of the musical references in the bone people enter a general world of (often atonal) music and, in that capacity, perform a narrative function, there are also many found pieces from supposed musical canons. These compositions encourage the reader to hear in their mind's ear a known piece of music, to relive it as a shortcut to the familiar, and to re-imagine it in a new context. The found song imported into the text can act, then, as an index for certain cultural givens. At the same time, there is the effect of musician to take in account. In Musical Meaning Lawrence Kramer describes the way in which a song can be freed from its absolute meaning by the presence of the musician and by the musical event, which supersede what is being sung or played causing a "withdrawal of meaning" from the song (52-53). Fictional music and fictional events, arguably, can withdraw meaning from a referenced song. Far from detracting from the power of singer and song, this phenomenon, according to Kramer, "converts the imaginary space occupied by meaning into the site of unfettered fantasy" $(60)$. Citing the symbolic usage of unoriginal music - that is, found music - Kramer calls on the transcendent power of music's associative tendrils: "Unoriginal music is one resource by which even the living may discover their capacity to live on in the present only differently" (287).

With these ideas in mind, the found compositions in the bone people can be read for their realist and fantastical possibilities. Aronson, reflecting in Music and the Novel that a writer's musical preferences are illuminated in their work, is amazed how many writers of the early twentieth century ignored folk music and avant garde twentieth century composers alike, in favour of Bach (Huxley), Beethoven (Forster and Mann) 
and Wagner (Proust) (Aronson 37-38). Joyce alone, claims Aronson, "responded to musical experiments" both high and low, from nineteenth century operetta arias to folkballads to Wagner. In this Joyce is like Shakespeare. A similar eclecticism is apparent in the bone people.

Where Hulme's characters' traits are highlighted by their association with things Kerewin's obsessiveness and isolation by her collections of artifacts, Simon's by his stealing - the characters are also affected by and reflected in the musical compositions gathered around them. In similar vein, Barthes makes a demarcation between types of representation, that is object and the abstract - where point-of-view is concerned: "In the threatre, in the cinema, in traditional literature, things are always seen from somewhere" (76). The found compositions in the bone people constitute points of reference seen by - or heard by - its characters.

\section{Track 1. Sea shanty (bone people 11):}

In Chapter 1 of the novel proper, Kerewin, ensconced but not very comfortably in the local pub, knocks a coin on the counter to get the attention of the barman. Engraved on the coin, the New Zealand fifty-cent piece, is Captain Cook's Endeavour. Kerewin imagines a parody of a song, and the words easily summon a swashbuckling sea shanty:

This ship that sets its sail forever rigid on my coin is named Endeavour.

She buys a drink to bar the dreams of the long nights lying. The world is never what it seems and the sun is dying. (11) 
The ship in Kerewin's interior song heralds Simon's arrival. The fact that Simon is introduced by a shanty-like song and not, say, a pop song from the 1980s, suggests a view of settler culture as having visitor status. The sea shanty originates from sailors on whaling and other ships, some of whom ended up in Aotearoa.

Track 2. Atonal composition (6):

The strange music already hinted at in the openings lines of the novel crops up again, this time with more musical description, as the "strain that grew and crept like a thin worm through the harmony of their embrace." In the same way in which the shanty prefigures Simon, the shattering of harmony introduces the atonality he brings with him. This atonality is represented in Track 2 by Schoenberg's String Trio Opus 45: I.

Track 3. "Recuerdos De La Alhambra" (25):

With Simon is ensconced in her tower for the first time and his silence is becoming tedious, Kerewin amuses herself by picking up her guitar: “[...]thrum, golpe, golpe, rasguedo, and she launches into an ersatz flamenco rhythm," unwittingly beginning a conversation about tonality. The tonal flamenco - which comes from Spain, the home of guitar - is already not sounding quite as it should when it is beset by the loud rain. The raw materials of music from atonality can be extrapolated have already entered the tower, perhaps with the interloper, Simon.

Later in the first act, as Kerewin prepares for a pleasant evening of solitude (food, wine, a fire, and Julian Bream playing "Recuerdas De La Alhambra” by Francisco Tárrega) Joe rings to invites her to visit (109). Conflicted about whether she wants or 
needs company, Kerewin goes anyway: "Goodbye potatoes in their jackets, ham, and Bream, and dandelion wine...” The Spanish guitar comes second to human contact. Yet, in the closing stages of the novel, Kerewin lists Flamenco guitar as one of the few things she loves (423).

Track 4. "What Shall We Do With a Drunken Sailor?" (145):

In the lead-up to Kerewin's discovery of the violence, Simon helps himself to liquor at her tower and gets hopelessly drunk. Summoning another sea shanty which perfectly describes the situation - "What Shall We Do With a Drunken Sailor" - Kerewin puts Simon in the shower to sober him up, and the hiss and buzz of water signifies a difference in the possible tonality.

Track 5. "The Thieving Magpie" (151):

Later in the evening, Kerewin is struggling with her newfound realisation, and finds herself playing the Overture to "La Gazza Ladra" or "The Thieving Magpie," by Rossini. Coincidentally, Simon's bright pink music box, which Joe bought him at the tobacconist and which he plays "twenty times a day," is produced. It jangles the same tune. "The Thieving Magpie” equates literally, of course, with Simon's stealing, but there is a further association: it was one of the pieces in Stanley Kubrick's 1971 film $\underline{\mathrm{A}}$ Clockwork Orange. In this adaptation of the novel by Anthony Burgess the protagonist, a violent offender and lover of Classical music, is put on a desensitisation program whereby filmed violent scenes are played to him accompanied by music in the hope that his attitude to violence will be reprogrammed. The film attracted a cult following 
and the soundtrack was widely available, bringing "The Thieving Magpie" into popular culture. Its significance at this point of the bone people concerns not only stealing and violence; it is as if Simon, having shared his plight with Kerewin, makes a foray into her tonal world via the loved music box.

Kerewin picks out "The Thieving Magpie" the song out again on her guitar as she is recovering from her illness (427). Poignantly, this occurs just before her dream of being welcomed on the marae, which is to prefigure her return.

Track 6. “Sur Le Pont D’Avignon” (222):

With relations strained after Kerewin has confronted Joe about his violence, Kerewin is mulling over Simon's ancestry. ${ }^{11}$ She guesses French and, while the boy sleeps, sings the French folk song, "Sur Le Pont D’Avignon."

Track 7. "The Marseillaise" (223):

Kerewin argues with Joe, and as the guitar plays in counterpoint to their harsh words, the French national anthem, "The Marseillaise," appears under her fingers. It is all very tonal - "an arpeggio of harmonics," "a series of brisk minor chords" - but the very mention of Simon brings the harmony to a raw, atonal "zing," and more bickering causes Kerewin to put the guitar down altogether. 
Tracks 8 and 9. "Pack Up Your Troubles" and "It's a Long Way to Tipperary" (28992):

At the pub near the end of the fourth act, in the lead-up to the final assault on Simon, people are singing "Pack Up Your Troubles" and "It"s a Long Way to Tipperary," which Kerewin dismisses at first as "World War Two all over again" but cannot resist joining in (289). ${ }^{12}$ The symbolism of these songs for Maori is enormous, because of the heavy losses and bravery in the Maori Battalion during both wars, and because of the issues they raise about community and alienation - a Maori community, being used to fight a Pakeha war at devastating cost. The war songs come at a point in the novel when Kerewin is hovering on the brink of getting something she wants - a Maori community - but it is still frustratingly outside her reach. She does not fit in with the expectations of Joe's whanau. While the others sing the war songs, Kerewin "talks" all the way through - to herself in her interior monologue, to Joe, and to a drunken racist Australian who antagonises her. She seems to be showing her disdain for a Maori community that goes along with a Pakeha world, that would fight Pakeha wars.

Track 10. Reel (294):

Of the three songs that Kerewin sings in the pub, composed by her, Simon's Mead Reel is the only one that is identifiable as a type. As she sings this song (which in its traditional Irish form would not have had words) Kerewin enjoys Joe's bafflement at her lyrics, which connect Simon, alcohol and dance. These words seem to infer that Kerewin has never told Joe how she discovered the truth about his violence - the time Simon got drunk at the tower. The reel's lyrics, an anti-ode to the pleasures of wine 
beginning "E wine," are accompanied by tonal chords and a tonal melody that engage with the blurring qualities of alcohol ("lightfooted, lightheaded"), and which accordingly threatens to wobble off course ("only just catching its balance"). ${ }^{13}$

The other two songs Kerewin sings in the pub are not found songs; they do not exist in the world, but are made for the purposes of the novel. These two songs, however, stand out as significant compositions compared to the nameless, formless music of Simon's web and many of Kerewin's guitar attempts, so it is worth considering them alongside the found music. The second pub number is a response to calls from the floor. Kerewin introduces the song as being for Simon, while playing guitar chords that she interrupts with a "twang" and a "zang/ping, zaang/piing" (295). When she adds that the song is about someone who uses their hands to communicate, the crowd look meaningfully at Joe. There's a chorus which the crowd sing like "anarchists" implying a shouting that defies tonality (296). Through the song, Joe's heart weeps, and he is "sick to his stomach." The last pub song appears, on the surface, to be a simple tonal ballad, beginning with a sequence of major chords. The lyrics describe a vision of a blissful existence listening to birdsong, which would normally be atonal:

When I was young and tree was full, of sweetly singing birds, then full of heart was I with song, o'erpowering great for words. (296)

When the subject grows older she no longer relies on the birds: “[...] words for my song I began to find/and to the tune give tongue." The major chords here give way to a "wandering eddy of discordancy" and "a small bitter melody." Minor chords follow, 
and the song ends up back at its original tune. What seems to be suggested here is an earlier existence epitomised by the atonal birdsong, but that is inevitably marred by the "knowledge" of tonality, by the music of the world. Arguably, the first atonal, formless state has been occupied by Simon until quite recently; perhaps it was occupied at one time by Kerewin, and indeed by every young innocent.

Track 11. "Pavane for Dead Infanta" (327):

The last named found composition in the novel, Ravel's "Pavane for Dead Infanta," comes not long after the final assault on Simon, when Joe is visiting Kerewin. Kerewin, who by now is feeling remorsefully implicated in the assault, implies that the only reason she did not attack Simon herself after he kicked in her guitar was that she was not sure if she could stop: “[...]if I could have hurt Sim without killing him that afternoon, I would have hurt him." She says, but not by way of excuse, that her mother had given her the guitar. Holding a different guitar, a black one, close she picks out the Pavane. Ravel's composition, originally written for piano in 1899 , subscribes to the slow dictates of the dance form, and has a starkly tonal and elegiac simplicity. Kerewin plays it again that night, and seems to have forgotten the rest of her repertoire. It is this piece that Joe remembers in jail, and works over in his mind so often that he is able to play it automatically next time he picks up a guitar. After all trace of Simon has been wiped away - his physical presence and the tricky interventions of his atonality - only stark tonality, it seems, is left. 
Track 12. Karanga (428):

As she emerges from her underworld of despair and illness, Kerewin dreams of being welcomed onto a rebuilt marae. In the dream she walks towards the call of "Haere mai!" which is chanted first by a lone woman, then by many voices until it has a thunderous quality like the sea (428). ${ }^{14}$ The sound of the karanga will be instantly summoned by every New Zealander, Maori and tau iwi alike. That its few-noted span is overcome by the white noise of the sea at this point in the novel suggests an openendedness; that even when circumstances seem to have stabilised, change is always a possibility.

Track 13. Waiata (431-432):

In Kerewin's diary entry near the end of the novel, she turns back to tell us the end of the story - how she instigated the rebuilding of the marae, and how a community gathered around. Where once Kerewin was vulnerable to the unsettling pitches of atonality, where once she shunned community singing in the pub, now she is able to report that she was "singing with the rest inside the tight sweet hall[...]." What seems to be implied here is a waiata sung by Kerewin, with voices surrounding her. We have an impression of Kerewin held by not only the walls of the whare, but by the tightness of the a harmony that she is free to partake of. 


\section{e) The abstract atonal as the key to a world}

Where mention of these known compositions will spark, at least for some readers, a recognition of and unconscious response to formal and finite arrangements of music, references to atonal music in the bone people operate quite differently. There are two reasons for this: the first is that the atonal references are all general, that is, they do not include found, existing atonal compositions; the second is that atonal music is hard to remember. Even a previously heard atonal composition is almost impossible to commit to memory for more than a few bars. ${ }^{15}$ The effect on the unconscious of music you can't whistle - atonal music - will be a view of the unknown, the infinite, the abstract. Hulme uses this to narrative and symbolic effect. Throughout the novel she goes to some lengths to describe atonal sounds, such as when Simon sings to a dead bird and Kerewin first hears his web of music:

Then he sits back on his heels, keeping his mind dark, and sings to it. It is a thin reedy sound at first, nasal and highpitched. It is the only sound he can make voluntarily, because even his laughter and screaming are not under his full control, and it is as secret as his name.

The singing rises and builds atonically. (236)

Hulme names atonality here, for the one and only time in the novel. The label is fairly clinical, and it is the description of atonality - sounds that are not "under control" - that summons the unstable, unfettered abstraction that becomes so pertinent to the characters' journey. Bettina Knapp, in her study of the artist Kandinsky's relationship with words, describes the releasing principle of the abstract, or "a subjective desire to draw out a content or image from its usual habitat and to sever it from worldly connections. In doing so the usual connections could not be made" (82). When Kerewin 
hears Simon singing, inherently abstract descriptions of atonality set the reader free from the known, and release them into the unknown, or at least the not sure about. Ironically this serves very well to describe the risky, confusing negotiations between the characters and the world they inhabit. What atonality signifies here is an endless, centreless capacity for reinvention, a Pandora's box of pitch-making possibility for the characters expand into something spatial, infinite, web-like.

\section{f) Music as the equivalent of words}

Where this chapter began, at the meeting place of words and their generous metaphors, is also where it overlaps with the next chapter. Before considering the sound of the text, it is worth noting how musical words act as metonyms, opening doors onto new states of being.

Using linguistic leaps of association, Hulme thickens the imaginative texture of her characters' worlds by imbuing objects and qualities with music. The hours, for instance, "sing by" (74). Joe describes Simon's music as "[a] sound of darkness that seemed to sing..." (103). In Simon's dream of dead rabbits he "feed[s] them music" (203). In each of these instances, Hulme alludes to specifically atonal music; hours, darkness and food, being spatially conceived, imply an array of every possible note, as if these objects were receptacles for cubic measurements of notes.

What these musical metaphors do is interfere with our sense of reality. If we are able to believe that an hour, darkness or food can be musical, then we can believe new ways of being are possible for Kerewin, Simon and Joe. This is of course the same with any 
linguistic metaphor, but the use of musical terms is grist to the mill of the bone people's musical patterning. If, in the imaginative world the novel invites us to inhabit, music and objects can be synthesised to bring the conscious and unconscious together (in the way Knapp describes as "a giant awakening” [14]), if reality can cross-fertilize unreality, then our "negative capability" will be complete. And, from these musicolinguistic stand-ins it is a short trip to where the text abandons itself to its own music. 


\section{Chapter 5: the bone people's Verbal Music}

To write is to note down the music of the world, the music of the body, the music of time[...]

Hélène Cixous

\section{a) Addressing the listener}

This chapter is about what goes on at the most basic level of the bone people, or indeed of written language: how words on the page represent sound, how they resonate in our mind's ear, how they affect each other by association, and how they look. What is extraordinary is that this silent package of signs and symbols conspires to lead us into an imagined world of the aural, the visual and the conceptual. At such a grassroots level the bone people's engagement with atonality has its most primordial impact. While Hulme wove musical themes and symbols into the formal system of the novel, with voice her musical aesthetic is at one with her means of telling. Hulme is of course no stranger to engaging with the possibilities for language through sound. The bone people is her only novel to date. Most of her other books are poetry in a lyric style - $\underline{\text { Silences }}$ Between (Moeraki Conversations), Lost Possessions and Strands.

Any language art has a level of musicality inherent in its rhythms, articulated sounds and intonation. In a written text these elements are implied, and musicality takes place in the mind's ear. When a text uses language techniques seemingly deliberately to elicit a certain sound, it invites a musical reading. The act of reading such a text reconstitutes 
or brings to life arrangements of sound in time and space. Perhaps in the course of this process meanings are altered and sounds changed in the cross-fertilising way Scher describes in "Notes Towards a Theory of Verbal Music," where words give up some of their meaning when they are placed out of context, and where the implied sound of a word and its meaning carry on an exchange of give and take (35). Within this linguistic framework, Scher concludes, almost unlimited symbolism is possible. Knapp concurs, with her model of abstraction in which words taken out of their usual context lose their equilibrium in relation to their usual "surroundings" (82).

Any loss of equilibrium, however, must be temporary. The contextualising of words, like nature, abhors a vacuum. The following excerpt from the bone people shows that Scher's and Knapp's disassociated words, existing away from a grammatical centre, can form fleeting relationships with the words around them in an atonal manner:

Redbrown, redbrown as red chalk, earthcoloured reminder. "Stammel and murrey," she murmurs happily, "ruddle and madder and o solferino," hunting with gusto through the chest of chalks. (72)

The impact of these linguistic clusters and explosions on the reader is sieved through the learned filter of silencing; our gut responses to the world become, when reading a text, gut responses to representations, silence and implication. The writer who remains aware of this transference is able to work with what lies behind representation. In the remarks that precede the quotation at the beginning of this chapter, Helen Cixous makes a connection between the physical effect of music entering our bodies, and the imagined world: "There is a sort of extraordinary, sublime universality of music. A part 
of my work has its source in the same material. The sonorous material" (47). There is an important parallel between Cixous' "sonorous material" and music in the bone people. Working with the silent character of Simon and his relationship with the musically aware Kerewin, Hulme expands the very building blocks of writing - its silence and what lies behind that - linguistically and thematically through the novel.

Alongside the metaphorical use of silence, "real" silence is represented by white space on the page, the equivalent of rests in music and to "no-music" at the beginnings and endings of compositions. Because Hulme is a poet as well as a novelist, it can be assumed that she is attentive to the use of white space. In the bone people, despite its theme of silence, she restricts herself to the visual and rhythmic conventions of the novel; or perhaps it is that she shuns white space in order to make the bone people busy - noisy even - with sounds.

The process of summoning "sonorous material" can arguably be seen to operate at a sentence level. Where otherwise grammatically correct sentences are juxtaposed with each other, out of context, then a system of give and take, of loss of equilibrium is at play. Hulme uses this very system in the bone people, constantly rearranging an array of points of views, which resonate with and against each other.

By layering seemingly unrelated words and making jumps in point of view, the bone people tosses the grounding notions of word and sentence into the air, where they are caught by a web-like structure of new sound and new meaning associations. Importantly, these recast words make new and subtle meanings that could not be described in any other way. In her attentiveness to the relationships between sound and meaning Hulme, like Joyce, in the words of Aronson, "addresses the listener rather than 
the reader" (40). In an interview with Alicia Bartlett, Hulme recalls a comment by Irihapeti Ramsden which attends to the same idea; Ramsden likens the bone people to her own experience of being on a marae as a child, where chanting, and conversations in both English and Maori were interwoven with waking and sleeping (214).

Hulme is doing what Bill Manhire describes, in "Dirty Silence," as "codeswitching." Manhire is primarily discussing New Zealand poets in his essay, texts which are "a sort of conversation between words from different languages" (151). Although Manhire is talking about different modes of language, it is notable that the piece of writing he plucks as his prime example of code-switching is a piece of fiction by Hone Tuwhare, "Don't Go Past Me With Your Nose in the Air," in which not only are levels of formality placed cheek-by-jowl, but Maori and English as well (151). In this observation Manhire alerts us to the fact that Tuwhare - notably, a poet - is perhaps Hulme's biggest Maori influence. Like Tuwhare, Hulme's attendance the sound of the text is continual.

\section{b) Who's there?: point of view}

From the beginning of the bone people, the most insistent question the novel asks is, Who's talking? The Prologue, "The End At The Beginning..." opens with Simon's whirling, unfixed, illusory inner monologue, but at this point (unless the novel's existence outside the book has gone before it) it is impossible to tell who the monologue belongs to. We can tell in Chapter 1 that the narrator has changed by the wry, slightly carping, bolshy tone ("Wonder what would happen if I started singing out 
loud?" [11]). This is interspersed with description and dialogue in real time, and by rather lyrical responses to the sea ("The crayfish moved in silence through clear azure water" [12]). "Holmes" sometimes addresses herself in the second person: " "Holmes you are thick and unfit and getting fatter day by day." "(15). At other times, she talks in a Gollum-like third person: "Shall we be nasty and throw it out right now?' " (25). Register, we note, changes often, allowing each character more than one point of view of themselves and the world. Later, Joe's voice will join the fray, and Kerewin's diary will assert itself. But long before these additions, we already know that we will not be able to depend on point of view being stable, both between characters and within them. This technique is of course not new by any means. In its various forms it has been a hallmark of modernist literature, from Joyce to Woolf to Mansfield, from Rushdie to Patricia Grace. A recent and extreme example of multiple points of view is Peter

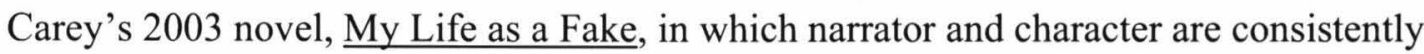
plowed into the same unpunctuated paragraphs. The bone people, like other works of fiction with varied points of view, teaches us how to read it by establishing its own parameters. We quickly learn to read with little or no expectation of a single view form "home," at least in the short term.

It is worth looking closely at how a changing point of view operates - inseparably from voice, as will be discussed below - for at least one character. Simon, who has been communicating with Kerewin sparingly by written sign, is revealed on page 32 to (probably) be the owner of the interior monologue in the Prologue, when he makes a starkly incisive admission to himself: "She don't like me around much./I'm staying 
though.” Later, Simon's view expands to include different modes. He recalls, for instance, an event from a seeming plethora of past traumatic experiences:

Two times ago, he had been trapped. And the young man, very young man, smooth and bearded, the young man who held his shoulder had pushed him hard against the upright of the fence[...] (72)

Simon's thoughts here encompass his own youthful speech patterns ("two times ago") while being filtered through a knowing omniscient narrator. As the novel progresses, Simon's inner world becomes as self-searching and allusive as Kerewin's, if not as frequently explored. Their thoughtful connection is on display in the lovely moment when Simon parodies Kerewin: "Where the unprintable as Kere says did I put that berloody jersey?[...]On ther berloody apricock floor" (177).

The omniscient narrator could be Kerewin who, with her diary, is the "writer" of the novel. But the text allows violations of its own rules. Joe, who has been the character mostly portrayed in real time - that is, his inner world has been explored the least breaks from this role in the chapter "The Kaumatua And The Broken Man" in which, after his final assault on Simon, he embarks on his own journey of both self abnegation and discovery. This chapter seems the least plausible in terms of voice because, although it is a toned-down version of a Kerewin-like voice, it leans too heavily on her idiom to be believably Joe's. On the other hand, the spiraling nature of point of view in the novel as a whole can also act to deliver Joe's chapter back at Kerewin's door as the novel's "author." Here, more than ever, point of view seems to be under the auspices of Kerewin, with Kerewin's sensibility operating as the central nervous system for the 
arms and legs of the novel. It is as if she, Kerewin the character, has given up the notion of clear centres.

The effect of these various and fluid points of view is important to the novel's music. A juxtaposing of voices, and therefore of timbre and tone, imports a constant sense of instability to the text. Even when patterns of layering and quick-change have been established, it is sometimes hard to grasp who is speaking or thinking. The reader is always on guard, listening for the changes of point of view that will decontextualise what has gone before, and for the unsettling clashes that result from words almost being put into other character's mouths. These decontextualising changes are inextricably bound up with voice because it is voice that will carry out or perform the changes.

\section{c) Fourworded wavespeech}

Hulme's greatest linguistic debt may be to Joyce, but it is only one of the many influences operating in the language of the novel. Working with linguistic parameters that allow the shifting and jostling of sound and meaning to infect each other, Hulme finds collections of language, and fashions them into new entities. We could think of the resulting structures as word hutches.

Chapter headings are a case in point. They are important to the way language structures the novel, providing a kind of rhythmic and linguistic punctuation. Already part of the musical fabric of the novel on a structural level as they move in a novelwide syncopated rhythm with turning points (noted in Chapter 3), the language of the 
chapter headings waves clear atonal signs. Each section bears a title that looks elsewhere from the places and way in which we expect to find language. "I Season Of The Day Moon," "II The Sea Round," "III The Lightning Struck Tower," "IV Feldapart Sinews, Breaken Bones" and the Epilogue, "Moonwater Picking" each subscribes to Scher's and Knapp's notion of rogue words, disassociated from each other and forming new meanings and implied sound relationships. The twelve subtitles are less metonymic and more like labels or quotations - "A Place to Sleep By Day," "The Boy By His Own.”

In the main text Hulme, roving around the many points of view engaged by the novel, sets up a range of linguistic motifs which are the coming into being of these points of view. One such motif is the jamming together, Joyce-like, of fistfuls of almost squeezable words, some of which are themselves the result of enjambment. A ring is "that barred charredlooking silver hulking hunk of thumbring" (21). In exasperation Kerewin inwardly curses Simon: “ 'O you icthyphagal numbskull' " (23). These wordjams are often precise in their descriptions: “[...]with a darting levering jab, stabbed, and a flounder flaps bloodyholed at the end of the stick" (14). Sometimes Kerewin performs verbal gymnastics seemingly for the sake of it, often after more than a few drinks: " 'One two three aleary hello my sweet mere hell these get steeper daily, days of sun and wine and jooyyy'" (15). (In this case she puns in Maori with the word, "mere," a short club.) The pile-ups of language are not restricted to Kerewin. Simon's sense of the unfixed nature of things (the atonal) is displayed in his revelation that names for things are nothing but ephemeral puffs of air: "Segment-lamanaria-vertebrae-lessonia- 
variegata-marauding-voodoo-korfie and ALL" (126). Compounds of words, rhymed words, odd words, are gathered as if in one of Kerewin's or Simon's collections, and the resulting tongue-twisters create new and otherwise indescribable meanings.

A further motif in Hulme's language arsenal is the use of cartoonish onomatopoeia such as "[c]lick buzz whirl" and "zang/ping, zaang/piing" $(23,295)$. These sounds establish the base of raw noise from which an alternative tonality is to emerge. In addition, mutated words like "Peeculeear," "Weelll" and "Hmmm" $(21,121)$ abound. Alongside this popular slang, there is swearing, which Kerewin performs in a fairly ladylike manner, with phrases like "Sweet apricocks and vilest excreta" (27). Frequent "sheeits" and "berloodys" are scattered through the text. Slang and cursing often travel next to formal modes in the text - descriptions of landscape, of inner thoughts, and of what happens. This technique works both to ruffle the text by contrasting modes, and to break down notions of proper and improper language. The effect is that the reader is never quite on safe ground; the sense of a linguistic home is ambushed. It is interesting to note, however, that in the first scene of the novel Kerewin expresses her distaste for the string of bad language uttered by the man in the pub, whom she does not know at that point is Joe, but which prefigures Joe's inarticulate violent rages: "I'd believe the poor effing fella's short of words" (12). Hulme appears to making an ethical demarcation between what is the rough-and-tumble of verbal play, and what is offensive.

When Hulme uses the Maori language in the bone people, it is often as part of an English sentence, reflecting common practice, but she also often includes entire sentences in Maori. Maori seems to be asserted as a separate language entity, existing 
alongside English in the novel. But perhaps there is more going on than parallel languages here; perhaps Maori and English in the bone people are influencing each other in musical ways. Brathwaite considers the "nation language" of the Caribbean to be based on song as much as word. He observes that when Caribbean English is written down, the result is a combination of Calypso rhythms and English stress-patterns such as pentameter. The "noise" that these combined patterns make, says Brathwaite, "is part of the meaning, and if you ignore noise[...]then you lose part of the meaning" (311-12). It is worth considering the possibility that Hulme's idiom combines the rhythms of Maori and English. Because I do not speak Maori beyond the rudimentary, this is a study I am unqualified to conduct.

If Kerewin's veritable sea of words recalls Joyce in general, the character of Stephen Dedalus in Portrait of the Artist as a Young Man seems particularly relevant. In his study of Joyce in Music and the Novel, Aronson attends to the musical revelation that comes to Stephan as he stands by the sea: "[...the sea is] the mother of all things, giving and taking life with equal indifference, rhythmically repeating the same message over and over again" (47). It is this white-noised revelation that results in the “fourworded wavespseech" that defines Stephen's relationship with being an artist in the world. By the time Joyce gets to Finnegans Wake he is using language like paint or a musical score, attempting, according to Melnick, to capture the rhythm of emotion, or "a pure expressivity formed by means of a musically conceived art" (108). In the same manner, Hulme's language at times appears to be an attempt to bypass meaning and arrive directly at feeling, as in this passage describing two antagonists, one of them 
Australian, involved in an argument in the pub, a contretemps which comes just before the final violent showdown between Kerewin, Joe and Simon:

He stalks away, his heavy paunch taut before him, fists ladling air at either side. The fifties-greasy grins apologetically, downs his beer, and scuttles off after. (294)

If we narrow the focus on considering language as verbal music in the bone people, having looked at sentence structure and word, we arrive at pure sound. The above passage uses a pedal effect - the prolonging of sounds - in the first few word, "stalks," "paunch" and "taut," to give the impression of an Australian drawl. Sibilants in "fists" and "side," in "fifties-greasy grin" are like hisses of anger. The final fricative "off after" alludes to explosive "effing." Hulme uses sounds to convey something over and above - or perhaps under and below - what mere words can import.

Knapp's close analysis of Joyce's short fiction "Eveline," from Dubliners, mines the story for its pure sound, its sonants. According to Knapp, Eveline's predicament of an unhappy family life, and her resolution to marry her sailor, are expressed in Joyce's “auditory experience," where sounds convey psychological association, feelings and moods (95-109). A similar music-making appears to be going on in the bone people. We have already seen how onomatopoeia plays a part in delivering raw sound to the novel, in buzzes, zangs and twangs. Orchestrated sonants deepen the auditory experience.

In the early days of the three character's encounters, Simon's sneakiness is written into sibilant sounds: 
The door is open.

He sidles inside.

He whistles as shrilly as he can.

No answer. (141)

When Joe is hopeful about a relationship with Kerewin, he calls to Simon internally with a string of prolonged vowels and soft sibilants: "Ahh tama, she likes us eh. She wants to be where we are, after all. It'll all work out fine, Himi, all work fine" (153). Joe's hopeful relaxation is evident in these sonants and in his chorus-like repetition. Jarring gutturals (“g," "gr"), plosives and alveolar stops (“d”) pepper the text not long after Kerewin has confronted Joe about his violence: "She removed the gills from the groper head, and put it in a separate bucket. Good for soup, and plenty of pickings in groper cheeks" (218). Around the time of the final act of violence, Kerewin is reduced to guttural explosions of rage and short breaths: "She loathes every particle of his being./Did he know what that guitar meant to her?/Did he know what her knife meant to her?" (307).

It would be impossible to mention every instance in the bone people where pure sound resonates outside itself, because almost every page is packed with emotionally charged sonants and rhythms. It appears, then, that sound plays a large role in how Hulme's language operates. By juxtaposing point of view to create diffusion and instability, by making arrays of linguistic motifs that jangle against each other in a simulation of atonality, by orchestrating with pure sounds, Hulme delivers the reader of the text an intensely musical experience together with its sidecars of meaning. 


\section{d) "I karanga to rivers"}

When Hulme makes the self-observation " $[\ldots]$ when I am traveling, I karanga to rivers, I call out to rivers," she is talking about the deep connections between music, place and time (1994 140). As noted in Chapter 1 of this thesis, the proper name of the karanga refers to a chant in which a kuia calls visitors onto a marae while at the same time recalling ancestors and setting the agenda for discussion, often in an illusory fashion (McLean 20). In her river-karanga, Hulme calls not from a specific location, but from the road as a traveler, and as she moves, so does the river. Nothing is fixed in this scenario, which is echoed in Spivaks's notion that the Centre is no longer analogous with the centre of town, but with the centre line on a road (1992 34). The view from the middle, according to Spivak, is always changing but is always with its subject. For Hulme, likewise, the view of the side of the road is an ever-changing, democratic renewal made possible by - and demanded by - atonality. Further, Hulme's description also takes into account the passage of time. "When I am travelling" incorporates not only the implied time it takes to travel, but the idea of a ritual repeated again and again across time. The karanga, then, is in Hulme's mind's ear; it is in the story that she tells us about it, and on the page that relates the story. It is portable and special, and if there is any marae, it is abstract. Hulme's voice in the bone people operates in a similar fashion, calling a world to the page.

It is the manner in which Hulme calls that embodies the aesthetic parameters and the emotion of the novel. Through voice, Hulme articulates the novel's political, narratological and cultural content. In the bone people, sound, metaphor and allusion function as a karanga, calling the reader to engage with the matters at hand - themes of 
loss, violence and transcendence. Hulme is the kuia calling the reader to re-chart the legacy of social and political struggle that has been the burdensome inheritance of neocolonial Maori. 


\section{Chapter 6: New Music}

\section{a) Interpreting harmony, noise and the atonal interlocutor}

The aim of this thesis has been to provide research on a hitherto ignored aspect of the bone people, its musicality; to use the findings to ask questions about the ongoing importance of the novel for today's readership, and hopefully to answer some of them.

A glance through Appendix 2 below makes it immediately clear that the bone people is packed with musical references. The preceding chapters reveal that Hulme allows music to enter the bone people through the inclinations of the characters, in particular through Kerewin's role as the failed woman artist who is "deaf" to real music and alive to a reading of music, and through Simon, the interloper. That the violent Joe is deaf to the metaphorical possibilities of music suggests that the real world alone offers no way forward from the characters' legacies of isolation and loss. Music, then, becomes the mode by which disruption and ambiguity enter the novel.

Music-in-literature as a discipline has been seen to encompass ways in which music can become part of the text's metaphorical work. Hulme engages with this branch of intermediality in cultural specific ways. In the bone people, she relocates traditional and contemporary functions of Maori chant and song to the page. The text of the bone people resembles a karanga, a call to the reader which charts an historical path, sets an agenda for discussion, and makes an argument.

The work of theorists writing on music-in-literature - Brathwaite, Melnick and Knapp in particular - has provided some important precedents for methodology in this 
study. In Chapters 3-5 the bone people's musical references are looked at from the point of view of narrative, symbol and sound. This study, then, has narrowed its focus, or zoomed in on, the various allusions to harmony, noise, and atonality, and has been specific about unraveling their content - that is, what kind of music occurs in the novel. Music, as we have seen - in particular by analysing the found compositions - is open to sets of fluctuating interpretations and associations, as in Bhabha's model of the Third Space where seeming cultural givens "have no primordial unity or fixity" (55). With this notion in mind, it can be observed that Maori and European allusions of all kinds, including musical, are drawn equally into the story-telling engine of the bone people.

This thesis contends that atonality in the system of the bone people deconstructs the notion of harmonic or Western tonality, and proposes the idea of its uncentred alternative. In its eschewing of a centre, the novel takes on the wider issue of cultural loss - of homelessness. By employing music to do this work in a written text, Hulme translates the political and societal functions of Maori music to the page. She calls the reader to the location of her text, which is not a fixed place, but is moving like a river.

We can see atonality at work clearly in the heightened episode when Kerewin dreams of being called onto the marae (428). In terms of narrative, the karanga prefigures emotionally the resolution to Kerewin's journey out of isolation. The karanga also functions in symbolic ways in the text: The chanting fits with the novel's privileging of the spiritual; it summons the archetypal for both Kerewin and the reader, who "knows" the sound of the karanga. On a language level, Hulme orchestrates collections of sonants and their associations which work on the reader in surprising ways. The dream-state is 
made aural with the pedal effects of the "eery hour when dreams are real" (428). Plosives and sibilants do their edgy work as "the light bursts into bright blue daylight." When Kerewin touches the doorstop of the whare in her dream, the building springs to life and "the other buildings [flow] out of it in a bewildering colonisation," and Hulme reclaims the pejorative term for the post-contact inheritance of Maori.

Before visiting the wider context for my claim, it is important to briefly review the parameters of this study. I am not suggesting atonality in the bone people directly references atonal works of music, or that readers will readily identify the twelve-tone music pioneered by the Second Viennese School - a music Said refers to as "Exiles' music - not only from the social world, but also from the tonal world" (2002 41). Rather, I propose that there is a symbolic and archetypal referencing of atonality in the bone people, and that the reader's experience of atonality in the text is a recognition of a temporal dislocation prompted by a jangling of scattered pitches.

It is also important to add that atonality, as a European concept, at least in its naming, is open to obvious limitations in its appropriateness for a reading of the bone people (see "A Note on Naming" in Chapter 1). At the same time, as a reader negotiating the apparent open-door policy on allusion in the novel (like Bill Manhire's ladder, the bone people, it seems to me, "longs to be lifted" [2005 19]), I note parallels with several key neocolonial and indigenous theorists.

The bone people's musical schema appears to illustrate, notably, Wendt's vision for creativity in a "new Oceania." Like Dening, Wendt argues against cultural purity and towards an inclusive view of traditional and contemporary cultural icons, values and 
practices (53). The use of harmony, noise and atonality in the bone people both mirrors and advocates Wendt's stance.

Hulme does what Brathwaite argues improvisation has achieved for the Caribbean novel; the marrying of "literature" (the written) and the traditional (the found) creates a fertile ground where physical sound and silent writing join to make a meaning beyond the writing. Barthes visits similar territory with his notion of the polarising process that divides peoples into performers or passive listeners (163); a process that has not made much headway in Maori society, where music is routinely used as part of social interaction. What Barthes further extrapolates from his player/listener argument is that the reader of the Text is, like the musician, also the interpreter; the reader, according to Barthes, is present at the event that is reading. The reader of the bone people, left in charge of an unpredictable, shifting and intertextual voice, arguably becomes the interpreter of the text in much the same way as the general populace on a marae takes part in the musical proceedings.

Finally, by positing a failed woman artist as a character and introducing atonality as a model, Hulme "acts out" Spivak's challenge to the notion of marginality. Hulme brings the culture of outside (Pakeha) into her own centre, which itself is vulnerable to change.

The issues uncovered by looking at music in general and atonality in particular in the bone people are important in the light of past criticism, which has often focused on the novel's perceived authenticity or lack of it. Aorewa McLeod, Mark Williams and Karl Stead, to name a few critics, have taken sides over the novel's ethnic purity. Other writers, like Otto Heim, Anna Smith and Graham Huggan have focused on how themes 
of violence, gender and ethnicity speak to a global postmodern world. More contemporary writings have come closer to examining the novel's Maori orientation, notably work on myth by Rod Edmond, and Janet Wilson's study of the abject in the novel. Overall there was been a tendency for Pakeha critics to interpret the bone people as a manifesto for a harmonious biculturalism (that is, to insert themselves into the text), a stance which appears to be changing.

Said's model of indigenous literature ruffling the "Western" view of how the "other" should be represented is at issue here (1994 291). It is perhaps true that in contemporary criticism, including that of the bone people, the disturbance occurs in different ways.

Connections between the bone people's atonality and the decentring notions of theorists raise some specific issues about the novel's take on neocolonialism. Hulme is not overt in her engagement with the political and cultural legacy of colonisation for Maori, in the way that, for example, Patricia Grace is. For Grace (and many other Maori writers, but with the exception of Tuwhare) systemic racism is often horrifically present. In Grace's model, the characters are seen to live side-by-side with the coloniser, in two parallel but interconnected worlds. In Hulme's version, Simon represents the coloniser in a less tangible manner (in a way that must be read); he is certainly the interloper but, like an early European arrival - a whaler, perhaps (he is the survivor of a boatwreck) - he is assimilated into Joe's, the Tainui's and finally into Kerewin's world. His child status is especially telling. It is notable, too, that there are no Pakeha adults among the main characters in the bone people, and no Pakeha society to be party to biculturalism. Simon's personal history is speculation only; his cultural imprint is confined to a set of rosary beads. He is not, and never will be (because of his 
brain damage and emotional wounds), in a position of power. Simon, far from representing political or even "cultural" biculturalism between the Maori and Pakeha, can only stand for assimilation.

Related to Simon's position is Joe's complex relationship with the Pakeha world - his at once loving and hateful feelings for Simon; his economic victimhood. Joe (who, it must be remembered, is the swearer from page 12) does not do anything as airy-fairy as fleeing to music; as a non-artist, he lives at the "real" interface with the Pakeha, and his journey is different and more polarized. At the new marae Joe, as guardian of the mauri and manual worker, lives a spiritual life and a practical one side by side. Joe's life embodies a dual tonality.

When Hulme talks of the bone people bringing "two quite different ways of thinking and two very different histories together" it seems, judging by an atonal reading of the novel, that she is not offering a bicultural solution (Alley 151). If the bone people suggests any way forward politically and culturally, it is that the real neocolonial world is hapless and impossible to negotiate, and that the only solution lies in the spiritual, the ambivalent, the atonal space.

\section{b) The first edition's children}

The life of the bone people since its publication twenty-four years ago has, in a sense, been comparable to the discussion following a karanga. As well as its ongoing critical impact, the novel continues to have a vigorous "bums-on-seats" existence. ${ }^{16}$ 
Hulme herself has made a plea for the transformations that the silent book can suggest. In her essay, "Mauri: an Introduction to Bi-cultural Poetry in New Zealand," she approaches biculturalism in its cultural rather than political sense. In this essay she certainly does not make any hopeful noises about the future of political biculturalism in Aotearoa. To the contrary, she catalogues the injustices served on Maori by colonisation, and makes an argument for poetry as a method of regaining identity and cultural ground. Citing the writings of kuia who adapted an oral tradition quickly to European-introduced literacy (specifically missionary-introduced), Hulme has high praise for a continuation of Maori culture in a contemporary framework: "The voice might die but the page (and so the spirit of the word) would live on" (295).

When Kerewin ventures into atonality, escaping the hegemonic language strictures described by Simawe (xxii), it begs the question, Where will an atonal language go from here? According to Said, there is no return from atonality (2002 49). In the bone people, Kerein and Joe do return to the marae, to stability, to tonality, as is indicated by the music in the closing pages of the novel. But is it really a return? A musical reading of the bone people shows a story that takes atonality into its maw, deals with the change it wreaks, and comes up with the possible co-existence of harmony, noise and atonality. The characters' final configuration suggests that new and novel ways of regaining, replenishing and invigorating culture will always need to be called upon. Kerewin, Joe and Simon do return to the marae, but they can never go back to how it was before. Instead, they will continue along Wendt's path of cultural evolution, living an culturally impure and changing life, but within a Maori framework. The novel itself was always on this path; it was the bone people's business to imagine the journey. 


\title{
Appendices
}

\author{
I: Glossary of Musical Terms \\ (Paraphrased from The Oxford Dictionary of Music, edited by Michael Kennedy, \\ except where otherwise shown.)
}

Arpeggio. A chord "spread," i.e. the notes heard one after the other from the bottom upwards, or sometimes from the top downwards, as on the harp.

Atonal. Not in any key, hence atonality. Usually applied when there is no tonal centre and the notes of the chromatic scale are used impartially.

Chord. Any simultaneous combination of notes, but usually of not fewer than 3 . The use of chords is the basic foundation of harmony.

Circle of fifths. An arrangement used to illustrate harmonic relativity. When notes are arranged in intervals of perfect fifths, they form a circle which incorporates all the 12 notes of the major and minor keys.

Coronach (also corronach). Highland Scottish and Irish funeral dirge.

Dirge. Burial or memorial song.

Discord. A chord which is jarring to the ear, requiring to be resolved in a particular way if its presence is to be justified by the ear.

Dissonance. See discord.

Frets. Strips of wood or metal on the fingerboard of certain instruments, e.g. the guitar. They indicate where to place the fingers to shorten the string and thereby change the note. 
Harmonic. Any note produced by an instrument is accompanied by a number of other notes at fixed intervals above it. These are heard as the constituents of the single note, but can be produced separately. On string instruments, including the guitar, this is done by touching the string lightly at various points.

Harmony. Notes sounded together to create vertical music, often supporting a melody, which is horizontal music.

Interval. The distance in pitch between two notes.

Karanga. 1. Call, shout (eed). 2. Maori chant of welcome to visitors, which includes references to ancestors, recent dead and subject of gathering (McLean 29).

Key. A composition in a certain key adheres to the notes of a particular major or minor scale.

Lament. Piece of elegiac music expressing grief, specifically music for bagpipes at Scottish clan funerals.

Microtone. Interval of less than a semitone; note in between the notes of tonal harmony.

Mode. Names for each of the ways of ordering a scale, e.g. major or minor. More often used to describe simpler, early European versions of these scales, based on Pythagoras' modes. They can be represented by playing the white notes on a piano.

Octave. Two notes at different frequencies, eight notes apart, that "sound the same," as when a group of people sing together and some sing high and some sing low, but on "the same note." The physical explanation for this is that the sound waves for each note are different but synchronised in terms of the Circle of Fifths.

Oro. Fixed intoning note or tonic. (McLean 235) 
Pavan (Fr. Pavane). Originally a stately Italian dance, popular in the $16^{\text {th }}$ and $17^{\text {th }}$ centuries. In duple (two-beat) time.

Plainsong. The body of traditional ritual melody of the Western Christian Church, in its final form called Gregorian chant.

Reel. Dance common in Scotland, Ireland and parts of England, for two or more couples. The music is rapid and flowing and generally in simple quadruple time. Requiem. The Roman Catholic Mass for the dead. Musical settings of.

Serialism, serial music, serial technique. Twentieth century technique of composition where tonal rules and convention are replaced with a structural, non-centric series of notes. A series, or note-row, would use all 12 tones of the chromatic scale in an order chosen by the composer.

Shanty. Sailor's work-song from the days of sailing ships, sung to a rhythm to aid work. "Shanty man" sang the tune and the others joined in the chorus. Famous examples are "The Rio Grande," "Shenandoah," and "What Shall We Do With a Drunken Sailor?”

Tonal. Of keys; key-centred. Opposite of atonal.

Twelve-tone music. See serial music.

Waiata. sing, chant, song, psalm, song poem. (eed) 


\section{II: Index of Musical References in the bone people}

[Indicates paraphrased text. ]

[...] Indicates intervening text.

p 3

[Simon's interior monologue.]

The silence is music.

$\mathrm{He}$ is the singer.

[...]

And she sings as she takes their hands.

p 6

In the beginning it was a tension, an element of strain that grew and crept like a thin worm through the harmony of their embrace.

p 11

[Kerewin drinks at the bar.]

This ship that sets its sails forever

rigid on my coin

is named Endeavour.

She buys a drink to bar the dreams

of the long nights lying.

The world is never what it seems

and the sun is dying [...]

Wonder what would happen if I started singing out loud?

\section{p 22}

[Kerewin is stuck with the intruder Simon until someone comes for him. As he sleeps in front of her fire and it rains outside, Kerewin recalls a family saying:]

"And ther rain" (shaking head slightly)

"was fair-lee piss (grimace and smash fist through the air)

"sing down (eyes wide with surprise at the violence of the rain).

The gusto, the singsong level of the speaker's voice made it real.

p 25

For a cat when in doubt, wash: for a Holmes, ruffle a guitar.

She takes her oldest guitar down from the wall, and picks a series of delicate harmonics to check the tuning. Then, the body of the guitar cuddled into her, she plays wandering chords and long pure notes and abrupt plucked melodies. The music melds into the steady background white noise of rain. 
At the end of it, she sighs, and props the guitar against herself.

"Do you like music, ahh, boy?"

His eyes are shut and his mouth is open, and she is unsure whether he is ecstatic or gone to sleep.

He blinks rapidly and nods, Yes.

$[\ldots]$

$[\ldots] \ldots$ thrum, golpe, golpe, rasguedo, and she launches into an ersatz flamenco rhythm.

p 26

She hangs the old guitar back on the wall, stroking its amber belly.

p 33

[While watches over Simon while he sleeps.]

She gets down her golden guitar, and plays low languorous chords, watching the night grow deeper all the while.

p 55

It is easy, leaning over the ambered belly [of the guitar], to put thought through a filter of slow-picked arpeggios.

p 56

[Joe has come to meet Kerewin to thank her for taking care of Simon, and Kerewin invites them to stay for tea. Because Joe has come straight from work, they shower first, while Kerewin plays the guitar.]

In the bathroom, Joe can hear the guitar, the rhythm of it rather than the chords: the walls are too thick for more.

"She can play... dry yourself," to the boy, as he begins putting on his own clothes.

p 60

"Moonraker, sunraker, o wild song for my ruby guitar," sang Kerewin, very quietly...

$[\ldots]$

([...]SHE PLAY THE GUITAR FOR ME) [Simon]

p 72

[Simon] had heard the door bang shut, and the sound of singing $[\ldots]$

p 73

[Simon goes into a musical reverie at Kerewin's tower.]

He can store any sound he wants to, and duplicate it inwardly.

$[\ldots]$

The only defence he could raise against the dark and the horror and the laughing terrible voice were his golden singers, the sounds and patterns of words from the past that he had fitted to his own web of music. 
p 74

[Kerewin draws.]

The hours sing by.

p 102

[Joe and Kerewin discuss Simon's music hutches.]

"You know what that reminds me of? Things Himi makes. Things he reckons make music." [Joe]

"O yes. The music hutches..." [Kerewin]

$[\ldots]$

[Kerewin recalls Simon asking her to put her ear near the spiralling grass structure he has built.]

Listened very intently, and was suddenly aware that the pulse of her blood and the surge of the surf and the thin rustle of the wind round the beaches were combining to make something like music.

[...]

She adds, "They only make music when someone's listening."

$[\ldots]$

(The child, when first discovered building [the music hutches], had written for him THEY MAKE MUSIC.[...])

p 103

[Joe calls Simon a nutcase, but later secretly listens to the music hutch.]

[...] he heard, thought he heard, a faint but growing music from Simon's creation... nothing he could really hear, a sound of darkness that seemed to sing...[...])

p 109

[...]Bream is playing Recuerdos De La Alhambra in the background.

$[\ldots] \ldots$ to drink and eat in peace, in music.

p 127

[Simon's music hutch]

[...] an odd little temple, a pivot for sounds to swing round....[...]

p 145

[Kerewin finds Simon has drunk her liquor.]

'What shall we do with a drunken sailor' [Lyrics to shanty]

p 150

[Where yarrowsticks for telling fortune are stored.]

[...] the niche by the guitars.

p 150-151

[After Kerewin has discovered Simon is a victim of physical abuse.]

She gets down the golden guitar for the second time this nightmare day, but this time picks out the ragged beginnings of a tune. Then it swoops, it flies, it glides... it sounds 
thin, only the guitar's voice singing the overture to La Gazza Ladra. It needs an orchestra, a synthesiser to do it justice. Or even that music box.

She opens the lid to the gaudy little box, and the melody jangles out... overture to The Thieving Magpie[...]

[Kerewin looks at Simon's pink music box.] "Okay taste in music but eech colour sense eh...[...]

p 165

[Joe arranges their gear at the holiday bach.]

On the other top bunk, he's put their suitcases and the two guitars.

p 199

[On the first day at the bach Kerewin has confronted Joe about his violence, and fought him in defence of Simon. That night, peace is restored as they cook together. Kerewin talks about her Aikido training and takes down her notes.]

She lifts down the guitar case, and takes a small book out of it.

p 200

She stands and puts the small book back inside the guitar case. The guitar strings hum faintly as the lid goes down.

p 203

[Simon finds dead baby rabbits and brings them back to life with music.]

So you start feeding them music, underbreath singing[...]The music rings and swirls now.

p 204

[Joe tells Kerewin about Simon's possessions.]

"There's two music boxes. A little pile of junk, mainly clock innards, and I think they all get fed into his crazy constructions[...]"

p 220

[Joe's violence is straining his relationship with Kerewin.]

[Joe] lays his guitar down and stands.

$[\ldots]$

Kerewin frowns and picks up the guitar... She runs her fingers over the strings, still frowning to herself.

p 221

Kerewin stops playing, zang in the middle of a chord.

p 222

[Kerewin questions Joe about where Simon came from.]

She starts picking a tune, watching her fingers now. "Because of that luverly reaction to my bastard French this morning [referring to Simon understanding French]... I was 
also going to casually sing the odd song, like this," a simple melody, "Sur Le Pont D'Avignon, and see if he reacted at all."

\section{p 223}

[Kerewin views her silence about the abuse as cowardly.]

The guitar begins to sing again in counterpoint to her words.

[...]Somehow the first bars of the Marseillais [sic] have sneaked into her playing. "I like ould Ireland, and I'll take care not to hurt him with words... it'll all be done with extreme and subtle care. The fish is in the freezer next door," an arpeggio of harmonics, "I took some photos of it more or less entire," a series of brisk minor chords, "though I don't suppose he wants to be reminded of it, eh," sing as she brings one high note skating down a dozen frets, 'e how?"

\section{p 236}

[Simon sings to a dead mollyhawk or toroa bird.]

Then he sits back on his heels, keeping his mind dark, and sings to it.

It is a thin reedy sound at first, nasal and highpitched. It is the only sound he can make voluntarily, because even his laughter and screaming are not under his full control, and it is as secret as his name.

The singing rises and builds atonically.

To Kerewin, walking catfooted on the silent sand, it has the strange heady purity of a counter-tenor.

She squats down three yards behind him and waits, not moving a muscle. Not even breathing loudly.

God, if only I had my guitar with me...

A green-armoured blowfly zzzes onto the mound and picks its way across the wet sand.

The singing stops.

p 237

[Simon discovers Kerewin can hear him singing, and he has nothing to fear.]

Nothing! She heard me singing! But nothing!

$[\ldots]$

Any time, I can sing!

$[\ldots]$

Icansing!Icansing!Icansing!

p 239

[Relations are strained between Kerewin and Joe.]

[...]Kerewin is playing something brutal and discordant.

Aue. If she feels like that sound... even Himi wouldn't like that.

And his child is now passionately, wholeheartedly, openly in love with music.' 
p 240

[Despite the tension, Joe marvels at Simon's newfound singing.]

("He's worse than the transistors," says Kerewin. "He's warbling along the beach like a demented canary... y'know a way to shut him up?" "No way! It's great," He's still not sure on all the details as to why his son has suddenly discovered he can sing "Well, port a beul, wordless mouth music," Kerewin the cyclopaedic - but he is as delighted and enthusiastic as the child with the ability. It's the only advance Simon has ever made, and besides, as Joe tells her repeatedly, "Sweet Lord, it's tuneful. He really can sing.")

\section{p 240-241}

He [Joe] listens to the savage tune Kerewin is throttling her guitar into producing, and thinks, I'll talk, but will she listen?

It's not blues, it's not rock, it's not folk or imitation electronic and sure as hell, it's not any Maori music he's heard before. He says, at the inner door,

"E hoa?"

Notes rear and slash at him.

"What are you playing?"

"Shark music," says Kerewin sweetly. "Dirges and laments, coronachs and requiems, all for my fellow sharks."”

He shudders.

She feels like that?

p 242

[Kerewin is upset by her brother's visit. Joe tries to help.]

"What's wrong? What can I do?"

"I'm just playing bad music and -

[...]

But she leans against the bunk post, and lets the guitar rest bellydown on her knees.

p 243

[Joe secretly desires Kerewin, while Kerewin is tortured by her collusion in the abuse.]

She fits the guitar back in its case and bangs down the lids.

p 252

[Simon sees a ghost.]

but the ghost is singing

E tama, $i$ whanake

i te ata o pipiri

$[\ldots]$

The lullaby is the ghost's goodbye.

p 262

[Joe sounds out Kerewin on making a family together.] 
"Sim at Tainui's still?"

"Yeah, being spoilt. Everyone thinks he's looking great. And he was showing off his singing about two seconds after we got in the door. Regular party there now."

\section{p 274}

[Kerewin, depressed by her keeping of Joe's secret, gets drunk.]

And here I go,

knocking around the bottle,

holding my heart open and

hoping my mind

keeps closed....

Tuneless bellowing, Holmes....

p 276

She wets the rim of the bubbleglass, and strokes round and round slowly. The crystal begins to sing.

"Getta guitar?"

\section{p 289}

[At a pub gathering, Kerewin discovers the Tainuis knows about the violence, and that there has been talk about she and Joe getting married. In the toilet she imagines memories passing out of her.]

$[\ldots] \ldots$...eep the sweet things, the first flows of joy at colour and shape and sound (chime of tuis, lichen at Moerangi, rich cadmium yellow on black and red rock; the ratpad ticker of the clock that beat time time time to my guitar[...]

$[\ldots]$

[An old lady comes into the bathroom.]

"They're starting to sing out there. Someone brought in a guitar. Does you good to sing eh?"

"Too right!" Her face is going scarlet.

$[\ldots]$

In the bar, there's a crowd gathered round the person playing, and the way is clear to their tables.

"Pack up your troubles," everyone is roaring beerily," and SMILE! SMILE! SMILE!

Sweet hell, here we go, World War Two all over again.'

p 292

[Joe is upset when Kerewin laughs at the idea of them as a couple.]

"We'll go and drink by the bar eh? Have a song or two before we go?"

'Singing is the last thing I want to do.

$[\ldots]$

"Okay man," she is saying. "Singing might stop the swirl in my head, eh?"

$[\ldots]$

[Kerewin has drunk heavily to forget her discomfort.] 
The guitarist is playing, "It's A Long Way To Tipperary," thunka thunka thunk, and the people round are bellowing out the words. She joins in, her strong voice roughening as she tries to outshout everyone.

Farewell Pic[c]adilly! and a germane part of her drink-unsteady mind begins a strange battle paean,

Ho! the godly scarlet crump of newborn bomb craters resounds above the

on gleeful whistling bullets whee! and the gurgling of cheery throttlings going and on...

\section{Goodbye Leicester Square!}

... a tuneful chrrkchrrkkk of thumb-blocked throats serving as a discreet melodic line below the sshpluck! of impact and the Ur! of pained surprise... ahh, rustling crumpling figures, blending folding fugueing (hands

he spreadfingered clutching Why?? delicate belly entrails flopping softly o he he!) a resonant yet subtle percussion...

It's a long long way to Pic[c]adilly

...o splurge life! Encorporate cheerful death! Enjoin dismemberment! O! blissful! Ahh! happy war!

\section{but my heart's right there!}

\section{p 294}

[Kerewin asks to borrow the pub musician's guitar.]

She checks the tuning swiftly, harmonics lingering in the air until she cuts them short with the flat of her hand.

On the open strings she picks a quick tune, says to Joe laughing, "I call this Simon's Mead Reel, though you don't know about that," chords A minor, while he shakes his head in bewilderment, and then she sings,

Ewine,

puts a fog upon the mind.

drowns down those hard old memories

to a thin blear line,

e wine...

Fingers dancing over the strings, changing the tune an octave lower:

Ewine,

through the cloud I see

him walk away from me, 
but I'm gone beyond the caring time,

zing, and up again,

E wine,

e wine...

a reeling tune, lightfooted, lightheaded, only just catching its balance as it slips and dances;

Ewine,

just a shade that's left behind

caressing this hard bottle as I please,

drinking my shadow blind,

E wine...e wine...e wine...

voice trailing away, the quick picked tune going lighter and lighter and lighter it's gone...

p 295

[The drinkers in the pub clamour for another song.]

"This is a song for a friend of mine, same one as I mentioned before as a matter of fact. You might know him,"

a note of jangles, seemingly mispicked, but it comes again and again, until all ears are hearing it more than the surrounding chord.

$[\ldots]$ a higher note has started to ring against the first jangle... zang/ping, zaang/piing, they duel back and forth, and the steady throb of the chords goes on underneath.

$[\ldots]$

[Joe's] heart is beating painfully heart, the thud going against the rhythm of the guitar, faster and louder in his ears.

[Joe fantasizes about a sexual relationship with Kerewin, then becomes aware of the song.]

The song has been going on but his ears have been deaf to it. The chorus has been caught up by the people around him., and is boisterously chanted complete with gesture.

O spirals are spirals and sweetly curled,

but two straight fingers can vee the world.

p 296

[The crowd calls for another song, and Kerewin complies, saying the song is for Simon.]

A simple chord sequence, D A7 G...

$[\ldots]$

When I was young and tree was full,

of sweetly singing birds, 
then full of hear was I with song,

$o$ 'erpowering great for words,

the key changes, slides into a dischord,

Not so now....

Her voice is unrestrained, no longer outshouting the crowd, pleasant alto, easy on the ears.

When me and the tree were older both,

and birds had left their young,

words for my song I began to find,

and to the tune give tongue,

again the wandering eddy of discordancy,

With a vow....

Aiee, it's a gentle song, he thinks[...]maybe it's all right....

That all the good would sunlike shine,

and beckon me ahead,

but in grey age for my past I pine,

with years my vow is dead,

the small bitter melody again,

Forgotten now....

That's the way it happens, he thinks, we start out bright and something clouds us...[...]

p 297

The chord sequence changes, Dm Am, E, is hit harder,

Lightning blasted the tree,

the birds are fled;

Death hovers here for me,

Yet not all hope is dead...

a ragged arpeggio, and then slowly the notes wind back to the original tune. Silence all round the bar, spread to tables beyond.

$[\ldots] \mathrm{He}$ waits for the change to sing with her.

$O$ when I was young and tree was full, 
he joins in, his bass mellowing the song further, and Kerewin smiles to him,

of sweetly singing birds,

then full of heart was I with song,

o'erpowering great for words....

The last chord dies into silence.

p 298

[Kerewin has stopped singing and Joe, drunk, is getting obstreperous.]

"Outa way![...]my lady troudabour is back!"

The original guitarist is thumping out a the coke-song, and all the pub is rocking with the tune.

p 305

[Kerewin and Simon fight over the stolen knife.]

[...]before she guessed what he was going to do, kicked in the belly of her amber guitar, lying there by the window.

The room became deathly still.

Huge pale blisters rose and spread under the varnish. The wood was smashed but the strings hung free, still humming in the air.

p 315

[After Joes final attack on Simon, Kerewin packs up her tower and reflects on how Simon might have been without all the trauma.]

A musician, full of zany fire? The dancer, she sweet singer, the listener to the silence of God on deserted beaches - ae, you had music in you.

\section{p 316}

Everything has been packed away now. The livingroom circle is[...]spartanly furnished. Two stretchers[...]some cooking gear; one sheepskin mat in front of the fire; Kerewin's black guitar on the wall.

\section{p 317}

She plays her guitar infrequently, and the music is always dispirited and sad. It has the kind of loneliness behind it that haunts old graves. Forgotten, dead, gone... she knows a lot of that kind of music.

\section{p 324}

[Joe, not yet convicted, visits Kerewin. He has a wound where Simon stabbed him.]

"Joe, do us a favour please?"

"Whatever you want."

"Pass us down the guitar... I seem to have grown roots here."

As he lifts the instrument down, she hears him grunt with pain.

He brings the guitar back and lays it by her: his face is rigid. 
"Fretting you?" she brushes the air by her belly in a gesture the child could have made.

p 326

[Kerewin feels remorseful that she didn't listen to Simon on his last visit.]

"Sim came here and kicked in my guitar as you know, but I provoked that. I kept interrogating him, no other word for it, as to where he'd put my bloody knife."

\section{p 327}

"The intent is $\sin$ as much as the action, and believe you me, if I could have hurt Sim without killing him that afternoon, I would have hurt him... hell, I was wild." Her fingers are plucking the guitar strings lute fashion. "So stupidly wild... I could buy a thousand guitars like that... it was just that it was special. The second guitar I ever owned - I literally played the first to death - and even given to me by my mother. I used it as comforter and cocelebrant and resonance chamber for my thought for over twenty years...."

She settles the black guitar body close to her, and begins to play.

It's a slow haunting tune; melancholy, yet it embraces the listener, drawing one onward rather than down.

He remembers it in the months to come, playing it so often in his mind that when he next picks up a guitar, his fingers settle into the melody without him meaning them to.

"Pavane for a dead infanta, by Ravel," she says at the music's end. She plays it again that night, seeming to have forgotten all the rest of her repertoire.

p 330

[Kerewin is packed up and ready to leave the tower.]

The suitcase, and the Ibanez [guitar] in its travelling case, are sitting by the locked Tower door.

p 341

[Joe considers a remorseful suicide.]

A three-note saw, a whining vicious singing: Jump Nga Kau.

p 417

[Diagnosed with cancer, Kerewin packs a few things for facing death, including.]

The Ibanez in its travelling case, with a spare set of silver strings.

$[\ldots]$

Sweet weed, sweet wine, sweet taker-out of self, I have you all, she sang to herself.

p 418

[Kerewin awakes with a hangover.]

'Little febrile clots of words

that choir in earfuls

humping off the page.' 
p 419

[Kerewin stays in a hut to wait for death.]

She has a sudden desire to play her guitar. But two days ago, she had sent it to her family's home. No letter, just the Ibanez.

Now the need to take the dark and pale between her arms, pearwood surface and ebony underbody. The black neck fretted with silver. Recollection of the palace of shadows.

O God, even my guitar wore mourning.

[...]

In a long effortful day, she hitched into the nearest town and bought a new guitar, two crates of whisky, and three cartons of foodstuffs[...]

p 420

[Still ill, Kerewin gathers magic mushrooms in the bush.]

At evening, she lit a fire, and made the only cooked meal of her day. She would paint, or write as the mood took her, all the pain down. Notes for a mushroom dealer. And then, until the fire died, would strum the guitar, or pluck untunes, or simply hold it in weeping hands.

[...]And once, high and uncaring under the benefice of the mushrooms, she caught herself laughing at the way a bead of pus leaked from the bend in her wrist down her sloping forearm onto the guitar's strings.

p 421

[Playing her new guitar.]

Trying the guitar... I could get to love this badly varnished parody. For it gives me back music, music to match the images of my mind, to draw them out and make a realm of exultant leaping joy.

p 423

"What do I love?" Musing on it.

"Very little. The earth. The stars. The sea. Cool classical guitar. Throbbing flamenco.[...]

p 427

[Feeling better, and having washed and cooked, Kerewin lies in front of the fire.]

$[\ldots]$ in between sips, practises scales on the guitar.

Nice to see those hands looking so neat... guitar's a hard funky sound, but you'll do, friend instrument, you'll do...

"You're lucky, Holmes, my harmonious soul. Not everyone gets second chances."

She thinks while her fingers slip into picking tunes.

$[\ldots]$

She steps lightly round the quagmire s and sinking sands of what comes next to the tune she picked in a long-ago pub, Simon's mead reel.

$[\ldots]$

[Musing on Joe and Simon.]

But as the overture to La Gazza Ladra swoops and sours and dips, 
I'll enquire. I'll see if I can be of use....

p 428

[Kerewin dreams of being welcomed onto a rebuilt marae.]

She walks to it, "Haere mai!" chanted by many voices now, filling the land like the thunderous pulse of the might sea.

$[\ldots]$

The karanga grows wilder, stronger.

$[\ldots]$

The land is clothed in beauty and the people sing.

p 429

[Kerewin leaves the hut and hitchhikes to the whanau baches.]

She packs all her gear next morning, except for the guitar and a bottle of whisky.

$[\ldots]$

Whistling to some words that have come into her mind, and wishing for a guitar to make it a processional, stick swung alongside instead, matching her east stride,

$O$, never silent by the sea

always something talking

water on rocks

water on sand

wind and birds

your heartbeat and

others' words

whatever knocks

keep right on walking

Listening is for free...

p 431-432

[Kerewin recounts in her diary how she instigated the rebuilding of the marae.]

They came with a keg, and blankets, and mattresses, and guitars[...]

[...] and I'm singing with the rest inside the tight sweet hall $[\ldots]$

p 441

[...]... someone's playing that accordion again, and there goes a guitar.[...]

The reedy song winds plaintively above the throb of the guitars.

It's the music and singing and talk talk talk...

p 442

[Joe, entrusted with the mauri, arrives at the marae and is looking for Simon in the whare nui.]

A wave of flat and heavy music drowns the homemade plunk and whine and chorus. Stereo blaring, ingots of sound beating the ears, people stirring fuckthisracket, louder louder LOUDER and someone bawls out and somebody else switches it off. Ahhh, snore, snore[...] 
p 443

Noise and riot, peace and quiet, all is music in this sphere.

$[\ldots]$

[Joe thinks Simon listens to the guitar because his own music has gone.]

In the early night, when it's still orderly, less of an orgy, Kerewin plays. The child listens on the fringes, but soon comes to her knee, leaning there, head down. His hair has regrown in fine straggling flakes and shades his crooked face: silvery moon hair pressed against the dark body of the guitar as he strains to hear the high notes sing. Kerewin, used to it already, plays on unmoved.

"What have I done," whispering it, crushing down his crying, "What have I done? I've taken away his music..."

"O, not all of it," says Kerewin the stony.

p 444

[Joe listens to Kerewin's familiar voice.]

"Ah sheet..." coming through a wall, over the buzzzz and jingle of music and talk[...]

p 445

[Joe watches Kerewin and suggests to Simon that they follow her.]

There she goes out the door, weaving round and singing to herself, guitar slung over her shoulder[...]

And there she stands, over the place, throwing sparks of words. All to a sly fastpicked tune, the mead reel, his dance, bring out last steps to her.

O the spun shiny surface

mica and stars,

I span: stand stunned

reeling over night and mind,

so far, no sand

or chance strange feeling

blunts my eyes blind... 


\section{Notes}

${ }^{1}$ While acknowledging the Pakeha-centricity of the term "necolonial" I continue to use it here because the search for a more appropriate term is outside the scope of this thesis.

${ }^{2}$ For a view of what it is to be Maori from the leader of the New Zealand Parliamentary Opposition, Don Brash, see New Zealand Herald 2 Oct 2006. 2 June 2007. <http://www.nzherald.co.nz/index.cfm?objectid=104039). Brash suggests that Maori as a distinct people "no longer makes sense [because] there are few if any people in New Zealand who have only Maori ancestors." The same newspaper cited a study which claimed Maori are statistically forty-three percent Pakeha (Oct 15 2006).

${ }^{3}$ Pakeha adult community music is seldom encountered outside religious expression.

${ }^{4}$ The painters Colin McCahon and Ralph Hotere re-imagined the texts of local poets. For an account of Douglas Lilburn's integrated response to the visual (in particular the work of Rita Angus) and the poetic into his compositions, see Douglas Lilburn: His Life and Music, by Philip Norman. Lilburn articulates the phenomenon as a "clarification of my intuitive feelings for space, colour, rhythms and forms of landscape somehow matching human experience, providing some valid analogue which can be mulled over in my musical machine."

${ }^{5}$ For the "Talking Chiefs" model see, Vilsoni Hereniko and Rob Wilson eds. Inside Out: Literature, Cultural Politics, and Identity in the New Pacific. Lanham, MD:

Rowman \& Littlefield, 1998. 
${ }^{6}$ The semantics here thingify disability. It is notable that the bone people does not do the same for Simon's disabilities; he is not his disablities, but he enacts them.

${ }^{7}$ One might add that these assets and services were built up under the Treaty of Waitangi; and that William's account is pertinent to the denial by the fifth Labour Government of New Zealand of a shared Maori/Crown jurisdiction over the New Zealand foreshore and seabed.

${ }^{8}$ Barthes refrains from including music, even sung, in this group, but it is not music we are talking about here. As Scher states, words in music operate differently from music in words.

${ }^{9}$ Reina Whaitiri, whose late father was a Kai Tahu leader (the same iwi as Hulme), describes dual power bases engaged in by Maori of necessity: "Our leaders were held in high esteem by the iwi, and at the same time might have what were considered lowly jobs in the Pakeha world, such as at the freezing works. It didn't matter. It was irrelevant. What mattered what their status in the iwi." (Reina Whaitiri in conversation, Jan 2007.)

${ }^{10} \mathrm{~A} \mathrm{CD}$ accompanying this thesis has renditions of music found in the bone people, both specific and implied. Where genres are implied in the novel (i.e., a sea shanty, atonal music, a reel, a karanga and a waiata) an example of the genre is included. A discography for the CD appears in Works Cited.

${ }^{11}$ For an account of Simon's ancestry in a short story, see Keri Hulme, "A Drift in Dream.” Te Kaihau/The Windeater. Wellington: Victoria UP, 1986.

${ }^{12}$ The songs are in fact First European War songs, as are most WWII songs. 
${ }^{13}$ Hulme's drinking song motif is self-mythologised in "Floating Words," a story from her recent collection of short fiction and poetry, $\underline{\text { Stonefish. }}$. The story has a character who sings Hulme's own "Winesong \#33" [10-11].

${ }^{14}$ Due to the difficulty of finding a recording of a karanga of Kai Tahu (Hulme's iwi), I have used a short Nga Puhi karanga which was recorded together with a waiata on a CD produced by Te Puni Kōkiri.

${ }^{15}$ As a student at Victoria University's Music Department I remember a professor, himself a twelve-tone composer, saying of a serial composition, "Well, you can’t whistle it."

${ }^{16}$ The bone people is listed on a number of "best" lists including: Second on Book News. “Best of the Bestsellers.” Booksellers New Zealand. April 27 2007. May 152007 $<$ http://www.booksellers.co.nz/bk_bst_bestof.htm>; Tenth on “The 50 Best New Zealand Books.” The New Zealand Listener 20 Mar. 2004. May 152007 $<$ http://www.listener.co.nz/issue/3332/artsbooks/1642> Fiftieth-equal with The Color Purple on The Guardian newspaper's 2003 fifty “Well Loved: Old Favourites and New Heroines.” Guardian. May 12 2003. May 152007. $<$ http://books.guardian.co.uk/news/articles/0,6109,954089,00.html> The bone people appears to morph between a general and a critical readership, being widely read on university courses and a favourite at literary studies conferences. In 2005 it was the subject of a seminar at the Stout Research Centre for New Zealand Studies to celebrate twenty years since its publication. 


\section{Works Cited}

\section{BY KERI HULME}

the bone people. Wellington: Spiral, 1983: London: Pan, 1986.

Hulme, Keri. Interview with Elizabeth Alley. In the Same Room: Conversations with New

Zealand Writers. Ed. Alley and Mark Williams. Auckland: Auckland UP, 1992. 141-56. Hulme, Keri. Interview with Rima Alicia Bartlett. Writing Across Worlds: Contemporary

Writers Talk. Ed. Susheila Nasta. New York: Routledge, 2004. 207-15.

Hulme, Keri. Interview with Harry Ricketts. Talking About Ourselves: Twelve New

Zealand Poets in Conversation with Harry Ricketts. Wellington: Mallinson Rendell, 1986. 17-29. Hulme, Keri. "Sandi Hall and Keri Hulme Talk About the bone people." Broadsheet 21 (1984).

Lost Possessions. Wellington: Victoria UP, 1985.

“Mauri: an Introduction to Bi-cultural Poetry in New Zealand.” Only Connect: Literary

Perspectives East and West. Ed. Guy Amirthanayagam and S. C. Harrex. Hawaii:

Centre for Research in the New Literatures in English/East-West Centre. 1981. 290-310. "Okarito and Moeraki." Te Whenua, te Iwi - The Land and the People. Ed. Jock Phillips.

Wellington: Allen \& Unwin/Port Nicholson Press/Stout Research Centre, 1987. 1-9.

"Reconsidering the bone people." Australian and New Zealand Studies in Canada 12 (1994). 135-154.

Stonefish. Wellington: Huia, 2004.

Strands [poems]. Auckland: Auckland UP, 1992. 


\section{ABOUT KERI HULME}

Arvidson, Ken. “Aspects of Contemporary Māori Writing in English.” Dirty Silence: Aspects of Language and Literature in New Zealand. Ed. Graham McGregor and Mark Williams. Auckland: Oxford UP, 1991. 143-57.

Cowley, Joy. "We Are the Bone People." Rev. of the bone people. The New Zealand Listener 12 May 198: 60.

Cozma, Codrina. "Joe Gillayley: A Model of Cultural Hybridity in Keri Hulme's Novel The Bone People." Journal of Maori and Pacific Development: He Puna Kaorero 5.1 (2004):-69-81.

Edmond, Rod. "No Country for Towers: Reconsidering the bone people." Landfall New Series 1.2 (1993): 277-90.

Fee, Margery. "Who Can Write As Other?" The Post-Colonial Studies Reader. Ed. Bill Ashcroft and Gareth Griffiths. London: Routledge, 1995. 242-45.

Hamelin, Christine. " 'Fitted to His Own Web of Music': Art as Renaming in the bone people." Australian \& New Zealand Studies in Canada 10 (1993): 106-20.

Huggan, G. "Philomela's Retold Story: Silence, Music and the Post-colonial Text." Journal of Commonwealth Literature 25.1 (1990): 12-23.

McLeod, Aorewa. “An Innocent's Look at New Zealand Women Writers.” Women's Studies Journal 2.2 (1986): 2-13.

Mita, Merata. "Indigenous Literature in a Colonial Society." The Republican. Pokeno, NZ: Republican Movement, 1984. 
O’Brien, Greg. "Pure Tang of Coast." Profile. Moments of Invention: Portraits of 21 New Zealand Writers. Auckland: Heinemann Reed, 1988. 21-26.

Quayson, Ato. "Looking Awry: Tropes of Disability in Post-colonial Writing.” $\underline{\text { An }}$ Introduction to Contemporary Fiction: International Writing in English Since 1970. Ed. Rod Mengham. Cambridge: Polity, 1999. 53-68.

Shieff, Sarah. "The bone people: Myths of Belonging." New Literature Review 41 (2004) 47-63.

Smith, Anna. "Keri Hulme and 'love's wounded beings'." Opening the Book: New Essays on New Zealand Writing. Ed. Mark Williams and Michele Leggott. Auckland: Auckland UP, 1995. 140-161.

Stead, C.K. "Keri Hulme's the bone people and the Pegasus Award for Maori literature." Answering To the Language. Auckland: Auckland UP, 1989. 178-183.

Williams, Mark. "Keri Hulme and Negative Capability.” Leaving the Highway: six contemporary New Zealand novelists. Ed. Mark Williams. Auckland: Auckland UP, 1990. 84-109.

Wilson, Janet. "The Abject and Sublime: Enabling Conditions of New Zealand's Postcolonial Identity." Postcolonial Cultures and Literatures. Ed. Andrew Benjamin, Tony Davies and Robbie Goh. New York: Lang, 2002. 300-19.

\section{GENERAL}

Aronson, Alex. Music and the Novel: A Study in Twentieth-Century Fiction. Totowa, N.J: Rowman \& Littlefield, 1980. 
Ash, Susan. "Scandalously In-Different? Janet Frame, Postmodernism and Gender." Opening the Book: New Essays on New Zealand Writing. Ed. Mark Williams and Michele Leggott. Auckland: Auckland UP, 1995. 123-139.

Bach, J.S. Well-Tempered Klavier. Preludes and fugues.

Barbera, André. "Pythagoras.” New Grove Dictionary of Music and Musicians. 2002. Grove Music Online. U of Hawai i, Hamilton Lib. 18 Feb. 2008. $<$ http://www.sinclair.hawaii.edu/music/>

Barthes, Roland. Image/Music/Text: Trans. Stephen Heath. $5^{\text {th }}$ ed. London: Fontana, 1984. Bhabha, Homi K. The Location of Culture. Classics ed. London: Routledge, 1994. Botstein, Leon. "Modernism.” New Grove Dictionary of Music and Musicians. 2002. Grove Music Online. U of Hawai i, Hamilton Lib. 18 Feb. 2008. $<$ http://www.sinclair.hawaii.edu/music/>

Brathwaite, Edward Kamau. "Jazz and the West Indian Novel." The Post-Colonial Studies

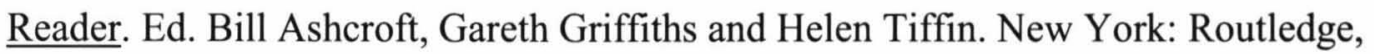
1995. 327-31.

Cage, John. 4' 3" Musical composition.

Cixous, H. Helene Cixous, Rootprints: Memory and Life Writing. Ed. H. Cixous and Mireille Calle-Gruber. London: Routledge, 1997.

Clockwork Orange. By Anthony Burgess. Dir. Stanley Kubrick. Warner Bros, 1971. Cook-Lynn, Elizabeth. “American Indian Intellectualism and the New Indian Story.” Natives and Academics: Researching and Writing about American Indians. Ed. Devon A. Mihesuah. Lincoln: U Nebraska P, 1998. 
Dening, Greg. “Afterword: On the Befores and Afters of the Encounter.” Cultural Memory: Reconfiguring History and Identity in the Postcolonial Pacific. Ed. Jeanette Marie Mageo. Honolulu: University of Hawaii Press, 2001. 205-15.

Drabkin, William. "Circle of Fifths." New Grove Dictionary of Music and Musicians. 2002. Grove Music Online. U of Hawai i, Hamilton Lib. 18 Feb. 2008. $<$ http://www.sinclair.hawaii.edu/music/>

Dryden, John. “A Song for St Cecilia’s Day, 1687.” English Verse. 26 May 2007 $<\mathrm{http}: / /$ www.englishverse.com/poems/a_song_for_st_cecilias_day_1687/>.

Espada, Martin. “My Father as a Guitar.” Alabanza: New and Selected Poems 1982-2002. New York: Norton, 2003. 178.

Haar, James. "Music of the Spheres." New Grove Dictionary of Music and Musicians. 2002. Grove Music Online. U of Hawai i, Hamilton Lib. 18 Feb. 2008. $<$ http://www.sinclair.hawaii.edu/music/>

Irving, John. The World According to Garp. 1978. New York: Ballantyne Books, 2000. “Karanga.” The Reed Dictionary of Modern Māori. Ed. P.M. Ryan. Auckland: Reed, 1995. Karp, Theodore. "Troubadours, trouvères III: Music.” New Grove Dictionary of Music and Musicians. 2002. Grove Music Online. U of Hawai i, Hamilton Lib. 18 Feb. 2008. $<$ http://www.sinclair.hawaii.edu/music/>

Knapp, Bettina L. Music, Archetype, and the Writer: a Jungian View. University Park: Pennsylvania State UP, 1988.

Kramer, Lawrence. Musical Meaning: Toward a Critical History. Berkeley: U Calif P, 2002.

McLean, Mervyn. Maori Music. Auckland: Auckland UP, 1996. 
Manhire, Bill. “The Ladder.” Lifted. Wellington: Victoria UP, 2005.

---, "Dirty Silence: Impure Sounds in New Zealand Poetry." Dirty Silence: Aspects of Language and Literature in New Zealand. Ed. Graham McGregor and Mark Williams. Auckland: Oxford UP, 1991. 143-157.

Melia, Daniel F. "The Lughnasa Musician in Ireland and Scotland.” The Journal of American Folklore. 80.318 (1967): 365-373.

Melnick, Daniel C. Fullness of Dissonance: Modern Fiction and the Aesthetics of Music. London: Associated UP, 1994.

Mitchell, W. J. T. "Postcolonial Culture, Postimperial Criticism.” The Post-Colonial Studies Reader. Ed. Bill Ashcroft, Gareth Griffiths and Helen Tiffin. New York: Routledge, 1995. 475-79.

“Music.” Def. 1.The Shorter Oxford English Dictionary. $3^{\text {rd }}$ ed. 1973.

Ngata, Apirina. Ngā Mōteatea: The Songs. Part I. Collected by Ngata. 1st ed. 1959. Auckland: Auckland UP, 2004.

“Noise." Defs. 1, 2 and 4. The Shorter Oxford English Dictionary. $3^{\text {rd }}$ ed. 1973. Norman, Philip. Douglas Lilburn: His Life and Music. Christchurch: Canterbury UP, 2006. Orbell, Margaret. Waiata: Maori Songs in History. Auckland: Reed, 1991. "Plainsong." The Oxford Dictionary of Music. $2^{\text {nd }}$ ed. 1994.

Said, Edward. Orientalism. Vintage Books ed. New York: Random, 1994.

---, Parallels and Paradoxes: Explorations in Music and Society. Said and Daniel Barenboim. New York: Pantheon, 2002.

Scher, Steven Paul. Word and Music Studies: Essays on Literature and Music (1967-2004) by Steven Paul Scher. ed Walter Bernhart and Werner Wolf. New York: Rodopi, 2004. 
Simawe, Saadi A. Introduction. "The Agency of Sound in African American Fiction." Black Orpheus: music in African American fiction from the Harlem Renaissance to Toni Morrison. Ed. Simawe. Border Crossings Vol. 9. New York: Garland Publishing, 2000. xix-xxv.

Sound of Music. By Maria von Trapp. Dir. Robert Wise. Songs by Rodgers and Hammerstein. Perf. Julie Andrews. $20^{\text {th }}$ Century Fox, 1965

Spivak, Guyatri Chakravorty. Interview with Leon De Kock. Ariel: A Review of International English Literature 23. 3 (1992): 29-47.

---, Outside in the Teaching Machine. New York: Routledge, 1993.

Strauss, Richard. Also Sprach Zarathustra. By Friedrich Nietzche. Symphonic Poem. op 30.

“Temperament.” The Oxford Dictionary of Music. $2^{\text {nd }}$ ed. 1994.

2001: A Space Odyssey. By Arthur C. Clarke. Dir. Stanley Kubrick. Metro-GoldwynMayer, 1968.

"Waiata." The Reed Dictionary of Modern Maori. Ed. P.M. Ryan. 1995.

Wendt, Albert. “Towards a New Oceania.” Mana Review. 1.1 (1976): 49-60.

Wolf, Werner. The Musicalization of Fiction: A Study in the Theory and History of Intermediality. Amsterdam: Rodopi, 1999.

LIST OF CD TRACKS (In order of reference in the bone people)

1. "Rio Grande." (Shanty.) Foc'sle Songs and Shanties. Perf. Paul Clayton and the Foc'sle Singers. Folkways Records, 1959.

2. Schoenberg, Arnold. "String Trio opus 45: I." Transfigured Night. Julliard String Quartet. Sony, 1992. 
3. "Recuerdos De La Alhambra.” By Tárrega. The Ultimate Guitar Collection. Perf. Julian Bream. Rec. 1975. BMG, 1999.

4. "What Shall We Do With a Drunken Sailor?” (Shanty.) Liverdance. Sheamus Fitzpatrick and the McNally Boys. Sheamus McNally, 2004.

5. “The Thieving Magpie.” By Rossini. Music for A Clockwork Orange, a film by Stanley Kubrick. All-Time Great Film and TV Themes. Vol. 1.Various artists. Associated Production Music, 2005.

6. “Sur le Pont D'Avignon.” J'ai Vu le Loup, le Renard et la Belette. Perf. Französische Kinderlieder. Carinco AG, 2005.

7. "Marseillaise.” By Victor Berlioz. Berlioz Arias. Perf. Robert Alagna. Deutsche Grammophon, 2006.

8. “Pack Up Your Troubles.” Oh! It’s a Lovely War. Vol. 1. Perf. Murray Johnston. LTM Publishing, 2005.

9. "It's a Long Way to Tipperary." Perf. Mance Lipscomb. You Got to Reap What You Sow: Texas Songmaster. Vol. 2. Arhoolie Records, 1993.

10. "The Dingle Set." (Reels.) Water From the Well. Perf. The Chieftains. BMG, 2000.

11. "Pavane Pour Une Infante Défunte." By Maurice Ravel. Bream Collection Vol. 11. Perf. Julian Bream. Rec. prior to 1972. BMG, 1994.

12. Karanga from "Waiata Te Horonga." Te Horonga. Perf. unknown. Te Puni Kōkiri, 1999.

13. "Ka Tahuri Au." Waiata from a series recorded during workshops held throughout Te Wai Pounamu, c. 1980. Courtesy Reina Whaitiri. 